\title{
Advancing the Frontiers in Nanocatalysis, Biointerfaces, and Renewable Energy Conversion by Innovations of Surface Techniques
}

\author{
Gabor A. Somorjai *, Heinz Frei, and Jeong Y. Park ${ }^{\dagger}$ \\ Department of Chemistry and Lawrence Berkeley National Laboratory \\ University of California, Berkeley
}

\begin{abstract}
The challenge of chemistry in the $21^{\text {st }}$ century is to achieve $100 \%$ selectivity of the desired product molecule in multi-path reactions (green chemistry) and develop renewable energy based processes. Surface chemistry and catalysis play key roles in this enterprise. Development of in-situ surface techniques such as high pressure scanning tunneling microscopy (STM), sum frequency generation (SFG) vibrational spectroscopy, time-resolved Fourier Transform Infrared (FT-IR) methods and ambient pressure X-ray photoelectron spectroscopy (AP-XPS) enabled the rapid advancing of three fields; nanocatalysts, biointerfaces, and renewable energy conversion chemistry. In materials nanoscience, synthetic methods have been developed to produce monodisperse metal and oxide nanoparticles (NP) in the $0.8-10 \mathrm{~nm}$ range with controlled shape, oxidation states, and composition, which can be used as selective catalysts since chemical selectivity appears to be dependent on all of these experimental parameters. New spectroscopic and microscopic techniques have been developed that operate under reaction conditions and reveal the dynamic change of molecular structure of catalysts and adsorbed molecules as the reactions proceed with changes in reaction intermediates, catalyst composition, and oxidation states. SFG vibrational spectroscopy detects amino acids, peptides and proteins adsorbed at hydrophobic and hydrophilic interfaces and monitors the change of surface structure and interactions with coadsorbed water. Exothermic reactions and photons generate hot electrons in metal nanoparticles that may be utilized in chemical energy conversion. The photo-splitting of water and carbon dioxide that are important research directions in renewable energy conversion is discussed.
\end{abstract}


* To whom correspondence should be addressed. E-mail: somorjai@ berkeley.edu

${ }^{\dagger}$ Current address: WCU Program, Graduate School of EEWS, KAIST, Yuseong-gu, Daejeon 305-701, Republic of Korea 


\section{Introduction}

Surface chemistry had a glorious 40 years during which it became an atomic scale and molecular level science. Using model surfaces, single crystals at first, the evolution of electron, ion and molecular scattering techniques provided atomic and molecular structures, composition and oxidation states and energy transfer information upon adsorption, desorption and scattering of molecules from surfaces ${ }^{1-4}$. Figure 1 shows the timeline of this development and evolution of surface science. Since these surface instruments required high vacuum and clean surfaces, surface chemistry at low pressures developed first. Then molecular surface chemistry developed by application of new experimental and theoretical techniques that permitted molecular level studies of all the other interfaces; solid-gas, solid-liquid, solid-solid, and liquid-liquid ${ }^{5-9}$. An up-to-date list of the surface techniques that lead to the evolution of surface science is shown in Figure 2. Since life on this planet does not operate in high vacuum the techniques that probe the buried interfaces opened up molecular level investigations of many applications of interfaces. Many of the surface chemists trained in our laboratories and elsewhere pursue research in these fields. For us, we were always fascinated by catalysis by surfaces such as transition metals and in the human body (which may be viewed as a polymerwater interface with a layer of adsorbed proteins). Fortunately both of these interface science applications are developing exponentially in recent years due to two entirely different reasons. The rise of nanosciences permitted the synthesis and characterization of nanoparticles and most catalysts, heterogeneous, homogenous and enzyme are nanoparticles. Heterogeneous transition metal catalysts are nanoparticles (NPs) with sizes in the $1-10 \mathrm{~nm}$ range and we could synthesize them with uniform size (monodispersed) and shape ${ }^{10}$. Figure 3 a shows the plot of the size of Pt nanocrystals as a function of $[\mathrm{Pt}(\mathrm{IV})$ to $\mathrm{Pt}(\mathrm{IV})+\mathrm{Pt}(\mathrm{II})]$ in the initial solution ${ }^{11}$. Figure $3 \mathrm{~b}$ and shows the shape control of Pt nanoparticles by adding $\mathrm{Ag}$ ions ${ }^{12}$. It was found that these $\mathrm{Ag}$ ions can be removed using nitric acid while the shape and size of nanoparticles remain the same. Figure $3 \mathrm{c}$ shows the shape control of $\mathrm{Pt} / \mathrm{Pd}$ bimetallic nanoparticles by adding oxygen gas.

Nanoparticles with controlled size and shape became our model catalysts after using metal single crystals for decades. As we find that selectivity depends on both NP 
size and shape, we can directly probe these as well as other molecular factors that make them nature's choice and the choice of chemical technologies as catalysts.

Biointerfaces are vital components of body implant chemistry as we are dramatically improving our life expectancy by replacing a failed organ or body part by an artificial one ${ }^{13}$. Figure 4 shows several frequently used replacement parts that are inserted daily in every hospital such as contact lenses, stents and prosthesis. The ability of the human body to accept these replacement parts (biocompatibility) is a major challenge and the driver of molecular level research in the field of biointerfaces.

The energy crisis drives the rapid developments in the interface chemistry of nanocatalysts. Production of one desired molecule that may be used as a fuel or chemical out of several thermodymically possible molecules that would be waste byproducts is called catalytic selectivity and it is the foundation of "green chemistry" ${ }^{14,15}$. In catalytic studies using model single crystal surfaces of metals we learned a great deal about the molecular mechanism of one-product molecule reactions such as ammonia synthesis, ethylene hydrogenation to ethane and carbon monoxide oxidation. However, selectivity in multi-path reactions are much more difficult to decipher. Figure 5 shows schematically a small shift in the relative heights of two potential energy barriers, of about $2 \mathrm{kcal} / \mathrm{mol}$, dramatically changing the product distribution ${ }^{16}$. Selectivity is the key component of energy efficiency in chemical energy conversion. By studying the selectivity in multipath hydrocarbon conversion reactions we find that it depends on both the size and the shape of the metal nanoparticles ${ }^{11,17}$ as well as other molecular factors that will be reviewed in this Perspective. One major challenge in our quest of renewable energy conversion is the use of sunlight to dissociate water and carbon dioxide. The state of research in these seminal fields of photochemistry utilizing nanoparticles is discussed. 


\section{Nanocatalysts}

\section{Studies that Focus on Model Catalytic Surfaces - Metal Single Crystals and Monodispersed Nanoparticles of Size 1-10 nm and Controlled Shape}

Single crystals have been used as model surfaces for both experimental and theoretical studies of metal catalysis. Ammonia synthesis ${ }^{18,19}$, CO oxidation ${ }^{20,21}, \mathrm{H}_{2} / \mathrm{D}_{2}$ exchange ${ }^{22,23}$ and ethylene hydrogenation ${ }^{24,25}$ were some of the important reactions that were studied on single crystal surfaces. Advances in nanoscience has made it possible to fabricate metal nanoparticle(NP)s in the $1-10 \mathrm{~nm}$ regime, which is the identical size range of the metal catalysts used as industrial catalysts ${ }^{26}$. As a result, model studies could be extended from single crystal metal surfaces to nanoparticles of controlled shape and size. Single crystalline metals used for modeling industrial catalysts inherently lack the complexity needed to uncover many of the factors important for catalytic turnover and selectivity. The most versatile way of fabricating nanoparticle catalysts uses colloid chemistry. By using a metal salt in solution such as hexachloroplatinic acid or rhodium acetyl acetonate as a precursor monomer ${ }^{27}$, it is possible to produce monodisperse metal nanoparticles, each coated with surfactant or a polymer layer that prevents their aggregation in solution. Under optimized reduction conditions it was possible to control the size and shape of the platinum and rhodium nanoparticles or bimetallic systems when these were fabricated ${ }^{28-30}$. Figure 6 illustrates the one-step synthesis of monodispersed $\mathrm{Rh} / \mathrm{Pt}$ bimetallic nanoparticles. By changing the stoichiometry of rhodium(III) acetylacetonate and platinum acetylacetonate, tuning of the composition of the bimetallic nanoparticles with $9 \mathrm{~nm}$ size was achieved ${ }^{30}$.

These monodisperse NPs with uniform size and shape can be deposited as a twodimensional film by using the Langmuir-Blodgett technique (Figure $7{ }^{31}$. The nanoparticles can also be deposited in a mesoporous three-dimensional oxide framework at much higher surface concentrations ${ }^{32,33}$ (Figure 8). Studies of these different NP arrangements show that they yield model surfaces that approximate the size and morphology of NPs currently used in chemical technology. Recently dendrimer encapsulated metal nanoclusters have been explored for catalysis ${ }^{34,35}$. The structure and 
chemical properties of dendrimers can be controlled by changing the core structure of these hyper-branched polymers, the number and type of the duplicating units and the terminal functional groups. Single metallic and bimetallic nanoparticles having dimensions less than $3 \mathrm{~nm}$ have been prepared within the cavities of these dendrimers. The many methods of characterization for studying two- or three-dimensional nanoparticles are listed in Figure 2.

\section{The Molecular Factors that Control Selectivity in Nanocatalysts}

Product selectivity is essential in developing processes that yield the desired molecules in multi-path reactions with complete selectivity. $100 \%$ selectivity, often called green chemistry, towards just one desired product molecule out of many thermodynamically stable molecules is the major challenge of the $21^{\text {st }}$ Century ${ }^{15,36}$. For multi-path reactions, instead of a single potential energy barrier that reflects the activation energy for the formation of a product there are several possible reaction products which have different potential energy barriers with small energy differences. The corresponding potential energy plot for the competitive formation of two products is depicted in Figure 5. The relative energy differences between the activation energy barriers determine the reaction selectivity. These differences can be induced by coadsorbates, small structural changes, or the addition of electron donors or acceptors, which change the binding energies of reaction intermediates. A small change in charge states of the metal catalysts (oxidation states) can also induce major changes in product selectivity.

It was found that catalytic selectivity during multi-path reactions on nanoparticle arrays depends on the size and shape of nanoparticles. Figure 9a shows the product selectivities during furan hydrogenation as a function of catalyst size and structure at 363K. The results reveal the higher selectivity of ring-opening for the larger the nanoparticle, and the exposure of more <100> facets. Over the $10 \mathrm{~nm} \mathrm{Pt}$ cubic nanoparticles butanol is formed only at lower temperatures, and vanishes at higher temperatures, while over the $1.0 \mathrm{~nm}$ Pt nanoparticles it is not seen at all. This is consistent with SFG-VS data on $\operatorname{Pt}(111)$ under furan hydrogenation conditions which 
shows that the planar furan ring lies parallel to the metal surface. Butanol is bound to the surface through the $\mathrm{O}$ atom, adsorbed in a parallel orientation. The surface concentration of butanol increases with increasing temperature over $\operatorname{Pt}(111)$, and THF is bound to the surface in an upright binding geometry. Over Pt(100) the SFG-VS spectra also indicate a parallel furan adsorption under hydrogenation conditions ${ }^{37}$. Both butanol and THF are seen bound to the $\operatorname{Pt}(100)$ surface in upright geometries. A similar trend was observed for pyrrole hydrogenation and ring-opening over Pt nanoparticles ${ }^{38}$. The smaller the nanoparticle, the higher the production of the partially saturated ring. These results are summarized in Figure $9 \mathrm{~b}$ which depicts dependence of the selectivity of the hydrogenation of pyrrole (4 Torr pyrrole, 400 Torr $\mathrm{H}_{2}, 413 \mathrm{~K}$ ) on the size of the platinum nanoparticles encapsulated in a dendrimer or $\mathrm{PVP}^{38}$.

The dependence of the selectivity of benzene hydrogenation on the shape of the platinum nanoparticles of the same size and single crystal surfaces with different surface structure was studied by Bratlie et al. ${ }^{17}$. Benzene hydrogenation turns out to produce two molecules: cyclohexane and cyclohexene on the platinum (111) surface while only one molecule (cyclohexene) on the (100) face. Similar trend was observed on nanoparticles arrays of different shapes (cubic and cuboctahedral). While cuboctahedra give rise to two products just like (111) single crystal surfaces, Pt cubes give rise to one product like the (100) single crystal surface. This result is summarized in Figure 10.

We have so far identified seven molecular factors that affect selectivity ${ }^{15}$; 1 ) surface structure, 2) adsorbate-induced restructuring, 3) adsorbate-mobility, 4) reaction intermediates, 5) surface composition, 6) charge transfer during catalysis, and 7) oxidation state of the catalyst. The understanding of the roles of these factors were enabled by development of new in-situ surface sensitive techniques, which we will describe next.

\section{Surface Techniques that Operate Under Reaction Conditions}

Since the 1980's researchers have worked to develop techniques that uncovers the structure composition and dynamics of surfaces at high pressure. The four techniques that we examine here in detail are ambient pressure X-ray photoelectron spectroscopy 
(AP-XPS) ${ }^{39,40}$, high pressure scanning tunneling microscopy (STM) ${ }^{41,42}$, sum frequency generation (SFG) vibrational spectroscopy ${ }^{43,44}$, and time-resolved Fourier Transform Infrared method (FT-IR) ${ }^{39}$.

\section{Surface Composition and Oxidation States under Reaction Conditions revealed by AP- XPS}

Surface composition is the key factor influencing the catalytic activity and selectivity of materials composed of two or more metals. The use of bimetallic nanoparticles allows the role of surface composition to be studied on the nanometer scale. The schematic representation of the APXPS experiment is shown in Figure $11^{39,45}$. It illustrates the differentially pumped electrostatic lens system that refocuses the scattered electrons into the object plane of a standard electron energy analyzer in the high-vacuum region. The kinetic energy of the detected electrons can be varied by tuning the photon energy of the X-ray source. This method permits the surface-specific XPS signal to be examined and the surface composition of the bimetallic nanoparticles to be determined.

Figure 12(a) and (b) show that the XPS results on rhodium/palladium and palladium/platinum 50/50\% bimetallic nanoparticles as a function of the kinetic energy of the X-rays, and shows the moderate surface segregation of rhodium and palladium, repectively in ultrahigh vacuum ${ }^{40}$. Figure 12 (c) and (d) shows AP-XPS data for rhodium/palladium and palladium/platinum 50/50\% bimetallic nanoparticles under oxidizing $(\mathrm{NO})$, reducing $(\mathrm{CO})$ and reaction $(\mathrm{NO} / \mathrm{CO})$ conditions, which directly shows the change of the surface composition as the reaction conditions are varied. The results suggest that rhodium atoms are pulled to the surface during the oxidizing conditions of the reaction. Under reducing conditions rhodium and the palladium surface compositions are roughly equal. These results indicate that the reaction conditions dramatically change the surface composition of bimetallic NPs. Because of their small size they undergo rapid random walk diffusion that will change the surface composition as the reaction conditions are varied. Thus the bimetallic system adjusts its surface composition to the type of reaction it catalyzes. 


\section{Surface structure, adsorbate-induced metal restructuring and adsorbate- mobility detected by HP-STM}

The adsorbate mobility during catalytic turnover has been observed by high pressure scanning tunneling microscopy ${ }^{41,46-48}$ (Figure 13a). No distinctive feature of the surface can be observed when scanning the surface at the rate of $100 \AA$ per millisecond during the hydrogenation/dehydrogenation of cyclohexene or hydrogenation of ethylene. All the adsorbed molecules on the surface, reaction intermediates and products, are more mobile under these conditions than the scanning speed of the tunneling tip. However, if the surface is poisoned using, for example, carbon monoxide the catalytic reaction stops and there are ordered structures formed on the surface as shown in Fig. 13b. The poisoning of the catalyst also minimizes the mobility of the adsorbate. In many cases, adsorbate mobility is required for the catalytic process to occur as the adsorbed reactants must find an active site, and that requires mobility on the surface. Thus the catalytically active surface is dynamic. High-pressure STM measurements show that adsorption of a gas such as oxygen, hydrogen or carbon monoxide, changes the structure of single crystal surfaces (Fig. 13c). During the chemisorption there is an increased coverage of the different chemisorbed molecules under pressure, which results in the number of chemical bonds between the adsorbate and substrate becoming greater. The reversibility of adsorbate-induced restructuring was readily observed by hydrogen adsorption/desorption or other chemisorbed gas adsorption and subsequent desorption ${ }^{49}$. After evacuating the chamber the original structure is once again obtained. Both the metal and the adsorbates restructure under the conditions of the catalytic reaction.

\section{Reaction intermediates detected by SFG vibrational spectroscopy}

SFG, a surface specific technique is based on similar principles as second harmonic generation ${ }^{50,51} 52,53$. Figure 14a shows a schematic representation of the experimental set-up for analyzing the catalytic reaction by high pressure SFG vibrational

spectroscopy ${ }^{50,54,55}$. In SFG two laser beams in the IR or visible region are spatially and 
temporally overlapping. Scanning the frequency of the IR laser enables the sum frequency signal and thus a vibrational spectra in the visible region to be obtained. Such a transition is symmetry forbidden for a centrosymmetric medium such as the bulk phase of a face centered cubic crystal or an isotropic high-pressure gas, or a liquid. However, at the surface the second order susceptibility is non-zero allowing the measurement of a vibrational spectrum that is sensitive to the monolayer. Such a spectrum can also give us vibrational frequencies of adsorbed molecules across a pressure range of 10-12 orders of magnitude.

The use of sum frequency generation vibrational spectroscopy enables reaction intermediates on the surface to be identified during catalytic turnover. By measuring the turnover rate as well as the SFG signals the kinetics of the reactions can be related to reaction intermediates. For example, in the case of the hydrogenation of ethylene some of the surface-bound species such ethylidyne and di- $\sigma$-bonded ethylene are spectators and they do not participate in the hydrogenation of ethylene ${ }^{56}$. Weakly bound $\pi$-bonded ethylene, which will be converted into ethane, is present at only concentrations of $4 \%$ in the monolayer. Figure $14 \mathrm{~b}$ shows the species that we see in the hydrogenation and dehydrogenation of cyclohexene. During this reaction, three reaction intermediates; 1,3cyclohexadiene, 1,4-cyclohexadiene and $\pi$-allyl molecule, are observed, all of which participate at different concentrations depending on the surface structure in the formation

of the product, cyclohexene or benzene ${ }^{57}$. High pressure SFG can also be used to study reaction intermediates on nanoparticle surfaces. For SFG measurements on nanoparticles, two dimensional nanoparticle arrays are deposited on a prism which allows for total internal reflection to increase the detection sensitivity ${ }^{58,59}$. Our recent SFG studies indicate that during hydrogenation of pyridine, pyridinium ions are the reaction intermediates and the formation of piperidine as the product of complete hydrogenation in the gas phase ${ }^{48}$. SFGVS of ethylene hydrogenation on the clean platinum nanoparticles after UV-ozone cleaning showed existence of ethylidyne and di- $\sigma$-bonded species, indicating the similarity between single-crystal and nanoparticle systems ${ }^{58}$.

Transient Reaction Intermediates revealed by Time-Resolved FTIR Spectroscopy 
A structure sensitive spectroscopy with temporal resolution ranging from nanoseconds to seconds for monitoring of heterogeneous catalysis over metal nanoparticles under practical reaction conditions is offered by the Fourier Transform Infrared method (FT-IR). To achieve such time resolution, initiation of the catalysis by a short reactant pulse synchronized with interferometric signal acquisition is required. This can readily be done for light-initiated reactions, and time-resolved FT-IR spectroscopy in heterogeneous environments using the step-scan method (nano and microseconds) was initially developed for photochemical systems ${ }^{60,61}$. For temporal resolution in the millisecond regime, the rapid scan method gives the best results. The technical challenge of applying time-resolved FT-IR techniques to catalysis is the delivery of a reactant pulse to the nanoparticle catalyst surface on a time scale that is short compared to reactive events of interest. Figure 15 shows the schematic of a reactor for time-resolved FT-IR monitoring of gas phase catalysis over supported metal nanoparticle catalysts at 1 atm and temperatures ranging from 295 to $700 \mathrm{~K}$.

For the search for transient surface intermediates of ethylene hydrogenation over alumina supported Pt nanoparticles, a gas pulse of ethylene was released from a fast mechanical valve that merged with a continuous flow of $\mathrm{H}_{2}$ diluted by nitrogen ( $1 \mathrm{~atm}$ total pressure, $4.5 \mathrm{~L} \mathrm{~min}^{-1}$ flow rate, $\mathrm{H}_{2} / \mathrm{N}_{2}=0.05,323 \mathrm{~K}$ ) in close proximity of the catalyst surface ${ }^{62,63}$. As shown in Figure 15, time resolved infrared spectra revealed instant growth of surface ethyl species $\left(\mathrm{CH}_{3} \mathrm{CH}_{2} \mathrm{Pt}, 1200 \mathrm{~cm}^{-1} \mathrm{CH}_{2}\right.$ wagging mode, 2870 $\mathrm{cm}^{-1} \mathrm{CH}$ stretch)) that decayed with a time constant of 122 milliseconds. The kinetics of surface ethyl decrease coincided with the rise of the gas phase ethane product $(\mathrm{CH}$ stretch band, Figure 15). The link between the temporal behavior of the two species established direct kinetic evidence for surface ethyl as the relevant reaction intermediate. This confirms that the barrier to surface ethyl hydrogenation is substantially higher than the preceding surface ethylene to ethyl hydrogenation step under reaction conditions.

For catalysis with metal nanoparticle catalysts supported on mesoporous silica, the time resolved FT-IR method allows the study of the diffusion and fate of reactants or 
products inside the nanoscale channels. When hydrogenating propylene over $\mathrm{Pt}$ nanoparticles $(1.7 \mathrm{~nm})$ supported on SBA-15 silica material, propane emerged inside the silica pores within 100 milliseconds $(383 \mathrm{~K})^{64}$. The $\mathrm{CH}$ stretching absorptions of propane inside the channels were distinct from the gas phase spectrum of $\mathrm{C}_{3} \mathrm{H}_{8}$, as shown in Figure 16. Spectral analysis allowed us to monitor the escape of the alkane product from the silica pores into the surrounding gas phase in real time, the first direct spectroscopic observation of emerging products of heterogeneous catalysis on a nanoporous support. Desorption of propane from the $8 \mathrm{~nm}$ wide, approx. one micrometer long channels was found to occur within 300 millisecond (1 atm, $383 \mathrm{~K}$ ).

\section{Biointerfaces}

The rapid evolution of the use of implants in the human body to replace or repair organs or body parts gave rise to research in biocompatibility to learn the body's response to accept or reject the implant. Figure 4 shows several implants commonly utilized in the medical practice. When a biomaterial is introduced into the body, one of the first events to occur is the adsorption of proteins from the surrounding fluid onto the surface of the implant. Because of the structural complexity of proteins, the use of model systems is now seen as essential to understanding these phenomena.

The surface modifications as they influence the interactions with proteins, peptides and amino acids in buffered water solutions were studied by SFG ${ }^{13,65,66}$. The amount of adsorbates on hydrophobic or hydrophilic surfaces were monitored by quartz crystal microbalance (QCM), that is an ultra-sensitive $\left(\mathrm{ng} \mathrm{cm}^{-2}\right)$ in situ mass sensor ${ }^{5,66}$. A QCM consists of a layer of piezoelectric quartz sandwiched between two conductive pieces of gold. Any material (such has silica or polystyrene) may be applied to the gold, providing a surface for molecular adsorption. An AC-field is applied across the quartz, causing it to oscillate at a characteristic frequency. As molecules adsorb from the surrounding medium to the crystal, the frequency changes. The Sauerbrey equation ${ }^{67}$ relates this change in frequency to a proportional change in the adsorbed mass, making a 
QCM one of widely used tool in the study of the adsorption of biomolecules. Another complimentary technique that is frequently used in biointerfacial studies is atomic force microscopy (AFM) which permits the study of surface topography and the measurement of surface mechanical properties, such as friction, adhesion, stiffness, and plastic deformation of the biomaterials. For example, protein adsorption on surfaces can also be characterized and measured with AFM ${ }^{68}$.

Figure 17 shows the surface vibrational spectra of poly-HEMA, a hydrogel commonly used as a contact lens material, when in contact with water and air ${ }^{69}$. Figure 17 (a), (b) and (c) shows SFG spectra of poly(HEMA) surfaces (a) at the water/polymer interface, (b) in hydrated state, and (c) dehydrated state. Figure 17 (d) depicts the change of molecular structure of poly(HEMA) during dehydration detected by SFG at the water/poly(HEMA) interface. The carboxyl groups segregate to the surface in water while the methyl groups segregate in air controlled by the hydrophilic and hydrophobic interactions, respectively. Thus, the surface composition changes with humidity.

Infection due to implanted biomaterials is a serious complication initiated by bacterial adhesion to the surface of the implant. To control the bacterial contamination, the polymer surface must be modified to reduce the bacterial adhesion ${ }^{70,71}$. The surface composition of polyurethane frequently used as an implant material can be altered using hydrophilic end-groups $\left(\mathrm{OH}\right.$ groups for example) or hydrophobic end groups $\left(-\mathrm{OCH}_{3}\right.$ groups) so-called surface modifying end groups (SMEs). Self-assembling monolayer end-groups (SAMEs) that are covalently bonded to the polymer during synthesis can also be used to modify the surface composition (Figure 18). By binding a molecule to the end of the alkyl chain that imparts antimicrobial activity to the SAME modified surface, the membrane of the bacterium compromised and the bacterium dies ${ }^{72}$. Surface modifying coatings can also enhance the thrombo-resistance or biostability of the polymer employing fluorocarbon SMEs.

A model short-chain peptide has been used to demonstrate the effects of the properties of biomolecule and surface on the adsorption orientation ${ }^{13,66}$. The model peptide, LK14, is an amphiphilic 14-amino acid peptide composed of hydrophobic Leucine (L) and hydrophilic Lysine (K) residues of sequence LKKLLKLLKKLLKL as shown in Figure 19(a). The LK14 peptide assumes an a-helical structure in a pH 7.4 
phosphate-buffered saline (PBS) solution with most of the hydrophobic residues pointing to one side of the molecule and hydrophilic residues to the other side. When the peptides are adsorbed to a hydrophobic deuterated polystyrene ( $\mathrm{d}_{8}$-PS) surface and a hydrophilic $\mathrm{SiO}_{2}$ surface from the PBS solution, SFG spectra show a marked difference (Figure 19(b)). The SFG spectrum at the PBS/ $\mathrm{d}_{8}-\mathrm{PS}$ interface is dominated by the $\mathrm{C}-\mathrm{H}$ stretch bands from the $\mathrm{CH}_{2}$ and $\mathrm{CH}_{3}$ groups, while, at the $\mathrm{PBS} / \mathrm{SiO}_{2}$ interface, only the $\mathrm{N}-\mathrm{H}$ stretch band is observed. The SFG results suggest that the hydrophobic interaction drives the hydrophobic methyl groups at one side of the peptide in contact with the hydrophobic surface to form an ordered layer of methyl groups, and that the disordered hydrophilic residues on the other side of the peptide form hydrogen bonds with water molecules. At the $\mathrm{PBS} / \mathrm{SiO}_{2}$ interface, the positively charged hydrophilic residues on one side of the peptide interact with the negatively charged $\mathrm{SiO}_{2}$ surface, and the $\mathrm{NH}$ end groups also form hydrogen bonds with the surface, which renders the N-H stretch band visible in the SFG spectrum. AFM and QCM were used to characterize the adsorption of a model peptide LK14 to both silica and polystyrene surfaces ${ }^{13,66}$. It was observed that at short times, the peptide adsorbs in small clusters, and the lateral dimensions of these clusters increase with time.

SFG vibrational spectra exhibit three different types of water structures (Figure 20) at the water-solid interfaces ${ }^{73}$. Since water is a coadsorbate with the peptide and protein molecules at biointerfaces one can monitor the role and nature of bonding of water molecules and how this influences the adsorbed biomolecule structure and orientation. Surface electrochemistry studies using SFG and FTIR indicate that adsorbed molecules change their orientation as the electrode potential is altered ${ }^{74}$. It is likely that the bonding of amino acids, peptides and proteins at the interface will be altered in the presence of changing surface charge. The fundamental surface chemistry of biomolecules influences increasingly the studies of biocompatibility of implant materials. 


\section{Renewable Energy Conversion Chemistry}

Development of reliable and renewable energy sources from abundant resources is one of challenges in the 21st Century. The principal renewable energy sources are biomass from plants, geothermal power from heat stored in Earth, wind energy, and solar energy from the Sun. Out of these, solar energy is one of the most significant and promising renewable energy sources ${ }^{75,76}$. Solar energy is converted to electricity by solar cells (also known as photovoltaic cells) or stored chemical energy via photo-splitting processes ${ }^{77-79}$. In this section, we describe the recent progress and challenges in energy conversion chemistry using nanomaterials with an emphasis of conversion of exothermic reaction or photon adsorption to hot electron flow using a nanodiode, and photo splitting of water and carbon dioxide.

\section{IV.a. Conversion of Exothermic Reactions and photons to Electron Flow at Metal Surfaces - Detection of Hot electron Flow with Metal-Semiconductor Nanodiode}

Fundamental mechanisms of energy dissipation and conversion at the surface and interfaces have been key issues in the surface science community. Energy dissipation at metal surfaces and interfaces is mediated by excitation of phonons and electron-hole pairs once the external energy is deposited to the surface during the exothermic chemical processes. Electron excitation in exothermic catalytic reactions or the incidence of photons at metal surfaces results in the flow of high energy electrons with energy of 1-3 $\mathrm{eV}$, assuming that most of the chemical or photon energy is converted to electron flow on a short, femtosecond time scale before atomic vibration dissipate energy adiabatically (in picoseconds) ${ }^{80-86}$. These energetic electrons that are not in thermal equilibrium with the metal atoms are called "hot electrons". These hot electrons move into the bulk of the metal catalyst, and eventually dissipate energy and turn into low energy electrons through lattice atom relaxation within the length scale of the electron mean free path, which is in the 5-10 $\mathrm{nm}$ range and within the lifetime of 10 femtoseconds. Recent experimental and theoretical studies have demonstrated electronic excitations created during atomic or 
molecular processes at surfaces. Theoretical models assuming that the nonadiabatic energy transfer during a surface chemical process is dominated by electron-hole pair excitations has been suggested ${ }^{87-90}$. Pump-probe experiments carried out on femtosecond time scales detect the presence of hot electrons in the metal ${ }^{91,92}$. When vibrationally excited molecules strike another surface they are rapidly de-excited because of hot electron formation. If the metal thickness or size is of the order of the electron mean free path, hot electrons can be collected during ballistic transport across the metal ${ }^{93}$.

\section{Hot electron generation from exothermic reaction and its detection with catalytic nanodiodes}

To detect this flow of hot electrons, we fabricated metal-semiconductor Schottky diodes. If the metal particle or film is of the diameter or thickness of the electron mean free path $(\sim 10 \mathrm{~nm})$ hot electrons can be collected as they are transported across the metal without collision as shown in figure 21(a) and 21(b). For an n-type Schottky diode, hot electrons are detected as a chemicurrent if their excess energy $E_{e x}=\left|E-E_{F}\right|$ is larger than the effective Schottky barrier, which is the difference between the conduction band minimum and the Fermi energy, $E_{F}$, at the interface ${ }^{83,85}$. Once hot electrons arrive at the oxide, they dissipate energy and thus cannot go back to the metal. Therefore, the Schottky energy barrier leads to irreversible one-way charge transfer of hot electrons from the metal to semiconductor. After hot electrons move from metal to semiconductor, they are replaced by low energy electrons supplied by the external leads connected to the $\mathrm{Pt}$ and semiconductor, resulting in the continuous flow of hot electrons generated by the catalytic reaction.

Schematics of the $\mathrm{Pt} / \mathrm{TiO}_{2}$ and $\mathrm{Pt} / \mathrm{GaN}$ nanodiode configurations that use surface catalyzed reactions to generate steady state current are shown in Figs. 22a and 22b, respectively ${ }^{94}$. In the first case, the bottom electrode, including a $50 \mathrm{~nm}$ adhesion layer of $\mathrm{Cr}$ or Ti and a $150 \mathrm{~nm}$ Au layer, was deposited through the first mask onto an oxidized ptype $\mathrm{Si}$ (100) wafer under $1 \times 10^{-6}$ Torr pressure by an electron beam evaporator. Then, 50 $\mathrm{nm}$ of $\mathrm{Ti}$ was then deposited on the top of the bottom electrode to form the Ohmic contact 
between the bottom electrode and $\mathrm{TiO}_{2}$ film. Next, a $150 \mathrm{~nm} \mathrm{TiO}$ film was deposited by sputtering through a third mask. A strip of $150 \mathrm{~nm}$ thick silicon nitride was then deposited through a fourth mask by plasma enhanced chemical vapor deposition (PECVD) at room temperature. Platinum of $2 \mathrm{~mm}$ in diameter with a thickness between 1 and $15 \mathrm{~nm}$ was then e-beam evaporated through a fifth mask onto the $\mathrm{TiO}_{2}$. Finally, the front gold electrode was e-beam deposited through the sixth mask onto the silicon nitride and the platinum to complete the diode circuit. Pt/GaN Schottky diode was fabricated through a standard microfabrication method. Platinum with a thickness of several nanometers was deposited through the mask on n-type GaN epitaxial layer grown on a sapphire substrate. A Schottky barrier is formed at the interface of $\mathrm{Pt} / \mathrm{GaN}$. Ti/Al layers were deposited on $\mathrm{GaN}$ to make the Ohmic contact between the GaN layer and the Schottky electrode. A quartz thickness monitor was used to monitor the film thickness during the deposition. The thickness of platinum films has been calibrated with profilometry and atomic force microscopy (AFM).

Figure 23 shows the TOF and chemicurrent detected on $\mathrm{Pt} / \mathrm{TiO}_{2}$ nanodiodes under $\mathrm{CO}$ oxidation conditions. The measurement of continuous chemicurrent indicated that chemical energy of exothermic catalytic reaction was directly converted into hot electron flux in the catalytic nanodiodes ${ }^{85}$. The chemicurrent was well correlated with the turnover rate of $\mathrm{CO}$ oxidation separately measured by gas chromatography.

\section{Hot electron generation from photon absorption on metallic film collected with metal-semiconductor Schottky diode}

The concept of photon energy conversion to hot electron flow was suggested by McFarland and Tang ${ }^{95}$. In this scheme, photons are harvested by dye molecules adsorbed on a Schottky diode composed of a thin gold layer on titanium dioxide $\left(\mathrm{TiO}_{2}\right)$. When light falls on the dye layer, electrons are released from the dye molecules and injected into the conduction band of the metal layer. The disadvantage of this scheme is the ineffectiveness of the adsorbed dye molecules in producing photocurrents. One reason for this is that electrons injected by the dye layer into the metal can be immediately 
recaptured through reverse charge transfer from filled electronic states of the metal into the dye, resulting in no net current flow.

By using metal-semiconductor Schottky diode, steady-state current from the continuous flow of ballistic charge carriers was measured that is generated by absorption of photons. The scheme and the energy band diagram of the photovoltaic device are also described in Figure 21a and 21b, respectively. To generate electric current through the device, these electrons need enough energy to travel over the Schottky barrier and into the $\mathrm{TiO}_{2}$ conduction band.

The short-circuit photocurrent was measured as a function of the wavelength of light on the metal-semiconductor Schottky diodes. Figure 24 shows the plot of the shortcircuit photocurrent as a function of photon energy measured on a $\mathrm{Pt} / \mathrm{TiO}_{2}$ diode with metal film thickness of $5 \mathrm{~nm}$. Photocurrent increases with increasing photon energy. In order to verify the relation between the hot electron flux and the photon energy, we fit the photocurrent to Fowler's law ${ }^{96,97}$. According to Fowler's law, the photoelectric current I is

$$
\mathrm{I}=\mathrm{c}(\mathrm{h} v-\phi)^{\mathrm{n}}
$$

where $\mathrm{c}$ is a constant, $\phi$ is the work function of the sample, and $\mathrm{h} v$ is the photon energy. For most metals, $\mathrm{n}=2$; other exponents apply to semiconductors. Figure 24 also shows the fit of photocurrent to Fowler's law with the fitting parameter of $n=2$ and $\phi$ (in our case, $\mathrm{E}_{\mathrm{SB}}$, the Schottky barrier height) of $1.2 \mathrm{eV}$. The fitting result shows that the measured photocurrent is in good agreement with Fowler's law. This result confirms that the measured photocurrent is mainly attributed to the hot electron flow, assuming that the contribution by defect states localized in the bandgap of $\mathrm{TiO}_{2}$ is ignorable. At high photon energy $(>3.2 \mathrm{eV}$ ), the photocurrent increases significantly, showing a departure from the Fowler's law fit, indicating the additional contribution of electron-hole pair excitation in titanium oxide. This result indicates that the steady-state flow of hot electrons generated from photon absorption can be directly probed with metalsemiconductor Schottky diodes. 


\section{IV.b. Heterogeneous Photocatalysts for the Splitting of Carbon Dioxide and}

Water

All-inorganic heterogeneous photocatalysts for the synthesis of methanol or other low alcohols from carbon dioxide and water as starting materials is an attractive approach for making a renewable liquid fuel by sunlight. The principal advantage of inorganic materials, especially oxides is robustness, a critical factor for developing viable solar fuel generators. In fact, early demonstration of UV light-induced splitting of water to $\mathrm{H}_{2}$ and $\mathrm{O}_{2}{ }^{98,99}$ involved stable oxides, such as $\mathrm{TiO}_{2}$ or $\mathrm{SrTiO}_{3}$. Very efficient and robust photocatalysts for overall water splitting by UV light based on metal oxides have been developed in recent years ${ }^{100,101}$. These include a La substituted tantalate with a NiO cocatalyst exhibiting a quantum yield of $56 \%{ }^{102}$. By contrast, visible light-driven overall water splitting with inorganic semiconductor materials remains a challenge. A successful photocatalytic material is $\mathrm{GaN}: \mathrm{ZnO}$ solid solution, but efficiencies remain low ${ }^{103}$. $\mathrm{GaInP}_{2}$ material serves as $\mathrm{H}_{2}$ evolution photocatalyst of an integrated photovoltaicphotoelectrochemical cell for overall water splitting that operates at high efficiency, but the materials lack chemical stability ${ }^{104}$.

For $\mathrm{CO}_{2}$ reduction by $\mathrm{H}_{2} \mathrm{O}$, early work with stable large bandgap oxides including $\mathrm{TiO}_{2}$ and $\mathrm{SrTiO}_{3}$ showed conversion to formic acid, carbon monoxide, methanol or methane under UV irradiation ${ }^{105,106}$. Reduction of $\mathrm{CO}_{2}$ is initiated by transfer of photogenerated conduction band electrons to surface-adsorbed $\mathrm{CO}_{2}$ or carbonate, while valence band holes drive oxidation of $\mathrm{H}_{2} \mathrm{O}$. Although product yields were low and the materials lack the visible absorption properties needed for use of sunlight, the work showed that activation of $\mathrm{CO}_{2}$ and $\mathrm{H}_{2} \mathrm{O}$ by bandgap excitation is feasible. Over the ensuing decades, efforts by the heterogeneous photocatalysis community focused on exploring smaller bandgap semiconductors for carbon dioxide activation by visible light. Particles or colloids with better donor ligands such as $\mathrm{CdS}$ or $\mathrm{ZnSe}$ afford $\mathrm{CO}_{2}$ reduction under visible light but are chemically unstable, requiring sacrificial reductants to suppress irreversible oxidation of the material ${ }^{107-109}$. The need for sacrificial reagents prevents the use of these materials for artificial photosynthesis. 


\section{Binuclear Photocatalysts on Nanoporous Silica Supports for $\mathrm{CO}_{2}$ Splitting}

With the emergence of nanoporous silica in $1990^{110,111}$, materials became available for developing well-defined photocatalytic sites for $\mathrm{CO}_{2}$ and $\mathrm{H}_{2} \mathrm{O}$ activation on nanostructured high surface area supports by functionalizing pore walls with single metal centers, heterobinuclear sites or well defined polynuclear clusters. For example, substantially improved conversion efficiencies were reported upon UV excitation of single tetrahedral $\mathrm{Ti}$ centers in mesoporous silica material type MCM-41 for $\mathrm{CO}_{2}$ reduction by $\mathrm{H}_{2} \mathrm{O}$ to methanol or methane, when compared with dense phase $\mathrm{TiO}_{2}$ particles ${ }^{112}$ (MCM-41 has a 1-dimensional system of channels of $3 \mathrm{~nm}$ diameter ${ }^{110}$ ). Insitu FT-IR and mass spectrometric monitoring of the photochemistry in the silica pores revealed $\mathrm{CO}$ and $\mathrm{O}_{2}$ as initial products and confirmed that $\mathrm{H}_{2} \mathrm{O}$ acts as electron donor ${ }^{113}$. Binuclear units consisting of metals with appropriate redox potentials for driving $\mathrm{CO}_{2}$ reduction or $\mathrm{H}_{2} \mathrm{O}$ oxidation catalysis assembled on silica nanopore surfaces open up opportunities to use visible instead of UV light for activating these molecules. In such a unit, e.g. $\mathrm{TiOCu}(\mathrm{I})$, visible light activates the metal centers by electron transfer from the donor center $(\mathrm{Cu}(\mathrm{I}))$ to the acceptor (Ti(IV). As shown in Fig. 25, the $\mathrm{Ti}(\mathrm{IV}) \mathrm{OCu}(\mathrm{I}) \rightarrow$ $\mathrm{Ti}(\mathrm{III}) \mathrm{OCu}$ (II) metal-to-metal charge-transfer (MMCT) chromophore gives rise to a broad absorption band extending across the visible spectrum to $600 \mathrm{~nm}{ }^{114}$. Infrared spectroscopy reveals bond modes of the covalently anchored binuclear site, and X-ray absorption measurements give insight into the coordination geometry of the metal centers (Fig. 25).

When exciting the $\mathrm{Zr}(\mathrm{IV}) \mathrm{OCu}(\mathrm{I}) \rightarrow \mathrm{Zr}(\mathrm{III}) \mathrm{OCu}$ (II) MMCT chromophore of the related $\mathrm{ZrOCu}(\mathrm{I})$ site in mesoporous silica MCM-41 loaded with $1 \mathrm{~atm}$ of gaseous carbon dioxide, splitting of $\mathrm{CO}_{2}$ to $\mathrm{CO}\left(2148 \mathrm{~cm}^{-1}\right)$ and $\mathrm{H}_{2} \mathrm{O}$ as coproduct $\left(1600 \mathrm{~cm}^{-1}\right)$ was observed at room temperature, as shown in Fig. $26^{115}$. Simultaneous depletion of the $\mathrm{Cu}(\mathrm{I}) \mathrm{O}$ infrared mode of the $\mathrm{ZrOCu}$ group at $643 \mathrm{~cm}^{-1}$ and growth of a $\mathrm{Cu}(\mathrm{II}) \mathrm{O}$ band at $540 \mathrm{~cm}^{-1}$ confirmed stoichiometric oxidation of the $\mathrm{Cu}$ donor center in this half reaction. Isotope labeling of the carbon dioxide molecule confirmed that $\mathrm{CO}$ and $\mathrm{H}_{2} \mathrm{O}$ are formed 
by splitting of the carbon dioxide molecule upon capture of an electron from transient $\mathrm{Zr}$ (III). This is the first observation of $\mathrm{CO}_{2}$ photoreduction at an all-inorganic binuclear redox site. Light-driven generation of $\mathrm{CO}$ from $\mathrm{CO}_{2}$ is the most critical step of the 6electron reduction to a low alcohol product.

\section{Polynuclear Photocatalysts for Water Oxidation with Visible Light}

Reduction of $\mathrm{CO}_{2}$ or oxidation of $\mathrm{H}_{2} \mathrm{O}$ molecules are multi-electron transfer processes. A general approach (and one used by Nature) for accomplishing visible lightdriven multi-electron transfer catalysis is coupling of a single photon, single electron pump to a multi-electron catalyst for sequential extraction (donation) of electrons to/from the catalyst. Nanoporous silica supports provide a synthetically flexible environment for assembling robust all-inorganic photocatalysts consisting of a heterobinuclear MMCT chromophore coupled to a metal oxide nanocluster catalyst. An example is a water oxidation photocatalyst consisting of a $\mathrm{TiOCr}(\mathrm{III})$ MMCT chromophore coupled to an $\mathrm{IrO}_{2}$ nanocluster, shown in Fig. $27^{116,117}$. The unit was synthesized on silica nanopore surfaces by sequential redox coupling steps, each highly selective ${ }^{116}$. Optical and EXAFS (extended X-ray fine structure) measurements shown in Figure 27 confirm the broad visible absorption and the oxo-bridged structure of the chromophore. The $\mathrm{IrO}_{2}$ catalyst clusters were directly observed inside the MCM-41 channels by high resolution Z-contrast TEM imaging coupled with energy dispersive X-ray spot analysis (Fig. 27). Ir oxide was selected as oxygen-evolving catalyst because of its high efficiency established previously by use as anode coating in electrochemical cells, and from chemical oxidation experiments with $\mathrm{IrO}_{2}$ colloids ${ }^{118,119}$.

When shining visible light on an aqueous suspension of MCM-41 particles containing $\mathrm{TiOCr}-\mathrm{IrO}_{2}$ photocatalyst units $(\mathrm{pH} 5.7,295 \mathrm{~K}), \mathrm{O}_{2}$ evolution was readily detected by an oxygen-selective Clark electrode, and a quantum efficiency of 13\% (lower limit) was derived from the measurements ${ }^{116}$ (Figure 28(a)). At the same time, in situ FT-Raman and EPR spectroscopy revealed the formation of superoxide species in the solution, and use of $\mathrm{H}_{2}{ }^{18} \mathrm{O}$ directly confirmed that water was the source of the $\mathrm{O}_{2}$ product 
(Fig. 28(b) and (c)). While performing the half reaction required the use of an electron acceptor (persulfate, which re-oxidizes transient $\mathrm{Ti}(\mathrm{III})$ to $\mathrm{Ti}(\mathrm{IV})$ ), irradiation of the photocatalyst in the absence of persulfate showed accumulation of Ti(III) based on EPR spectroscopic measurements (Fig. 28(d)). This observation implies that electron transfer from the $\mathrm{IrO}_{2}$ nanocluster catalyst to the transient $\mathrm{Cr}(\mathrm{IV})$ donor center is competitive with back electron transfer from $\mathrm{Ti}(\mathrm{III})$ even in the absence of an electron acceptor. The result indicates efficient electronic coupling of the catalyst with the binuclear chromophore, which is responsible for the good reaction quantum efficiency.

\section{Co Oxide Clusters as Efficient Water Oxidation Catalysts}

In addition to being efficient, an important property of the all-inorganic TiOCr$\mathrm{IrO}_{2}$ unit is its chemical stability. Yet, the photocatalyst would not be viable for large scale application because iridium is not an earth-abundant element. By contrast, oxides of metals like Co and Mn are known to exhibit catalytic activity for water oxidation when used as anode coatings in electrochemical cells ${ }^{119}$, or in particulate form when driven by a chemical oxidant generated either photochemically or directly added to the solution 118,120 . The previous works suggest that these abundant metal oxides might form robust, efficient nanometer sized catalysts for water oxidation if very large surface area nanostructured forms with highly active surface metal sites can be developed.

Using wet impregnation $\left(\mathrm{Co}\left(\mathrm{NO}_{3}\right)_{2}\right.$ in ethanol, 4wt\% loading) followed by controlled calcination, we prepared $35 \mathrm{~nm}$ size $\mathrm{Co}_{3} \mathrm{O}_{4}$ clusters consisting of parallel bundles of nanorods ( $8 \mathrm{~nm}$ diameter) interconnected by short bridges inside the pores of SBA-15 silica support, shown in Fig. 29(a)-(c) ${ }^{33}$. Close inspection of the TEM images of the clusters inside the silica scaffold and in bare form (after removal of the silica scaffold by etching) show that the nanorod bundles are perfect replica of the SBA-15 mesopore structure. XRD and EXAFS spectra confirmed the spinel structure of the Co oxide catalysts (Fig. 29(d)). Suspension of the SBA-15 particles containing $\mathrm{Co}_{3} \mathrm{O}_{4}$ clusters in aqueous solution ( $\mathrm{pH} 5.8$, room temperature) and driving the catalysts by visible lightgenerated $\mathrm{Ru}^{+3}(\mathrm{bpy})_{3}$ species (a standard technique for comparing efficiencies of various water oxidation catalysts) resulted in rapid evolution of $\mathrm{O}_{2}$ in the headspace of the 
aqueous solution as monitored by mass spectroscopy. As can be seen from Figure 29 (e) and (f), oxygen generation leveled off due to consumption of the persulfate acceptor, but resumed at the initial rate after adding fresh $\mathrm{S}_{2} \mathrm{O}_{8}{ }^{-2}$ acceptor. From these measurements, a turnover frequency (TOF) of $1140 \mathrm{~s}^{-1}$ per cluster was calculated (pH 6, overpotential 350 $\mathrm{mV}, 295 \mathrm{~K})$. Taking into account the geometrical projection of the $35 \mathrm{~nm}$ diameter cluster onto a plane, the TOF corresponds to $1 \mathrm{O}_{2}$ molecule $\mathrm{s}^{-1} \mathrm{~nm}^{-2}$. The high rate, mild catalytic conditions, low overpotential, robustness and abundance of the material make this a promising catalyst for water oxidation in solar fuel generating systems.

Comparison of the rates of $\mathrm{O}_{2}$ production of nanostructured catalyst clusters and micron-sized $\mathrm{Co}_{3} \mathrm{O}_{4}$ particles (Fig. 29(f)), normalized to equal weight, furnishes insight into the factors responsible for the high efficiency. The nanoclusters are 1550 times more efficient than the micron-sized particles ${ }^{33}$. Two factors contribute to the 3 orders of magnitude higher rate of the nanoclusters: A factor of 96 is due to the much larger surface area of the nanostructured cluster, with the additional factor of 16 attributed to the higher activity of Co sites on the steeply curved nanorod surface.

While we focus here on multi-electron catalysts in the form of Co oxide nanoclusters, there are other interesting recent developments in the field of all-inorganic water oxidation catalysts: Electrodeposits on anodes generated from Co phosphate solution were discovered to form a durable oxygen-evolving electrocatalyst that operates under mild conditions ${ }^{121}$. Polyoxometallates are emerging as another form of robust, allinorganiccatalyst for water oxidation ${ }^{122,123}$.

\section{Closing the Photocatalytic Cycle}

A crucial property of photocatalytic units made of a binuclear charge-transfer chromophore coupled to a multi-electron catalyst is the flexibility in selecting donor and acceptor metal center and oxidation state. The synthetic techniques for assembling the oxo-bridged units afford selection from a variety of abundant first row metals such as $\mathrm{Cr}(\mathrm{III}), \mathrm{Mn}(\mathrm{II}), \mathrm{Co}(\mathrm{II}), \mathrm{Ce}(\mathrm{III})^{114,124,125}$, which allows us to match the redox potential of the donor centers with the potential of catalysts driving water oxidation. This is essential for maximizing the fraction of the photon energy converted to chemical energy of the 
products, a persistent challenge in the development of efficient photocatalysts for artificial photosynthesis. The ability to carefully select the redox potential of donor and acceptor center of an MMCT chromophore is equally important for closing the photocatalytic cycle by driving the $\mathrm{CO}_{2}$ reduction with electrons generated by the water oxidation reaction. In order to accomplish directional electron transport from the water oxidation site to the $\mathrm{CO}_{2}$ reduction photocatalyst with minimum loss of energy, the redox potentials of the two photocatalytic sites need again to be carefully matched. The selective methods for assembling binuclear chromophores and metal oxide nanocluster catalysts in silica nanopores offer a new approach for addressing this long standing challenge.

\section{Conclusion and future perspective}

The development of techniques that use photons and electrons that are uniquely surface sensitive enabled researchers to determine surface composition, atomic and molecular structures, electronic structures, charge states, and reaction dynamics at surfaces in vacuum and buried interfaces, solid-gas, solid-liquid, solid-solid, and liquidliquid interfaces.

The rapid evolution of nanosciences made possible the synthesis of monodispersed nanoparticles with controlled size, shape and composition. Catalysts are nanoparticles in the 1-10 $\mathrm{nm}$ size range and reaction selectivity could be achieved by synthetic control of the molecular factors that influence reaction dynamics. This provides the foundation of green chemistry, the production of one desired molecule as fuel or chemical while suppressing the formation of other thermodynamically possible molecules that would be waste byproducts.

Biointerfaces that form when implants inserted in the human body must be biocompatible to function properly and this requirement guides the rapid advancements in the understanding of adsorption processes in this application of surface science.

Renewable energy conversion is the challenge of the 21 st century. Nanomaterials provide means to convert heat liberated in exothermic reactions or by absorption of light to 
electron flow. The photo-splitting of water to $\mathrm{H}_{2}$ and $\mathrm{O}_{2}$ and photosplitting of $\mathrm{CO}_{2}$ to $\mathrm{CO}$ and $\mathrm{O}_{2}$ are important directions of research. $\mathrm{CO}_{2}$ reduction with electrons generated by water oxidation would close the photocatalytic cycle and research is focused on using chemically stable inorganic catalysts.

As the techniques of molecular surface science become increasingly diverse and available, many other applications of surfaces and interfaces can be explored on the atomic and molecular scale. In addition to nanocatalysts, biointerfaces and renewable energy conversion that are the focus of this Perspective, electrochemistry, corrosion, tribology and colloids come to mind. As the surface techniques achieve improved time resolution, spatial resolution and energy resolution, new surface phenomena will be discovered. There are exciting opportunities to develop new science at surfaces and interfaces.

\section{Acknowledgement}

The authors acknowledge Wenyu Huang for his help. This work was supported by the Director, Office of Science, Office of Basic Energy Sciences, Division of Chemical Sciences, Geological and Biosciences and Division of Materials Sciences and Engineering of the U.S. Department of Energy under contract No. DE-AC02$05 \mathrm{CH} 11231$. 


\section{Figure Captions}

Figure 1. Evolution of surface science

Figure 2. A list of the surface techniques

Figure 3. (a) Monodispersed platinum nanocubes of 3.5-9 $\mathrm{nm}$ size, (b) platinum nanoparticles with uniform shapes controlled by addition of $\mathrm{Ag}$ ions, and (c) flow of oxygen gas induced selective adsorption on certain crystal faces. Reprinted with permission from ref 11. Copyright 2009 American Chemical Society.

Figure 4. Replacement parts that are inserted into the human body. (a) images of contact lenses, and (b) stent, (c) polyurethane, and (d) prosthesis.

Figure 5. Potential-energy plot depicting selectivity in heterogeneous catalysis. Small changes in the relative heights of the activation barriers as low as $2 \mathrm{kcal} / \mathrm{mol}$ drastically changes the product distribution. Adapted with permission from ref 16. Copyright 2002 American Chemical Society.

Figure 6. One-step synthesis of monodispersed $\mathrm{Rh} / \mathrm{Pt}$ bimetallic nanoparticles. acac $=$ acetylacetonate.

Figure 7. Schematic of Langmuir-Blodgett method and TEM image of 2D Pt nanoparticle arrays on silicon oxide surface fabricated with the Langmuir-Blodgett method

Figure 8. TEM images of Pt nanoparticles $(2.6 \mathrm{~nm})$ assembled into a mesoporousSBA-15 silica support by capillary inclusion method.

Figure 9. (a) Particle size selectivity dependence at $90{ }^{\circ} \mathrm{C}(10$ Torr of Furan and 100 Torr of hydrogen) and (b) dependence of the selectivity of the hydrogenation of pyrrole (4 Torr pyrrole, 400 Torr $\mathrm{H}_{2}, 413 \mathrm{~K}$ ) on the size of the platinum nanoparticles encapsulated in a dendrimer or PVP. Adapted with permission from ref 38. Copyright 2008 American Chemical Society.

Figure 10. (a) Turnover rates of cyclohexane $\left(\mathrm{C}_{6} \mathrm{H}_{12}\right)$ and cyclohexene $\left(\mathrm{C}_{6} \mathrm{H}_{10}\right)$ formation under benzene hydrogenation on $\mathrm{Pt}(100)$ and $\mathrm{Pt}(111)$ single crystals and (b) tetradecyltrimethylammonium bromide-stabilized cubic and cuboctahedral $\mathrm{Pt}$ nanoparticles for 10 Torr $\mathrm{C}_{6} \mathrm{H}_{6}, 100$ Torr $\mathrm{H}_{2}$, and 650 Torr Ar). Adapted with permission from ref 17. Copyright 2007 American Chemical Society.

Figure 11. Schematic representation of ambient pressure X-ray photoelectron spectroscopy 
Figure 12. (a) XPS results of rhodium/palladium and (b) palladium/platinum 50/50\% bimetallic nanoparticles as a function of the kinetic energy of the X-rays. Rh has the higher surface composition for $\mathrm{Rh}_{0.5} \mathrm{Pd}_{0.5}$ bimetallic nanoparticles, while $\mathrm{Pd}$ has the higher surface composition for $\mathrm{Pt}_{0.5} \mathrm{Pd} 0.5$ bimetallic nanoparticles. (c) AP-XPS data for rhodium/palladium and (d) palladium/platinum 50/50\% bimetallic nanoparticles under oxidizing (NO), reducing $(\mathrm{CO})$ and reaction $(\mathrm{NO} / \mathrm{CO})$ conditions, which directly shows the change of the surface composition as the reaction conditions are varied. From ref 40. Reprinted with permission from AAAS.

Figure 13. (a)The schematic of high pressure STM, (b) STM images revealing the progress of cyclohexene hydrogenation to cyclohexane and dehydrogenation to benzene on a Pt (111) surface at 350K. Left and right STM images show catalytically active and poisoned surfaces, respectively and (c) In-situ STM images reveal adsorbate-induced restructuring of $\mathrm{Pt}$ (110) surface in 1.7 atm hydrogen $(73 \mathrm{~nm} \times 70 \mathrm{~nm}), 1.0$ atm oxygen $(90 \mathrm{~nm} \times 78 \mathrm{~nm})$ and 1.0 atm carbon monoxide $(77 \mathrm{~nm} \times 74 \mathrm{~nm})$. Adapted with permission from ${ }^{126}$. With kind permission from Springer Science+Business Media.

Figure 14. (a) Schematic of high pressure SFG system, a vibrational spectroscopic tool for probing the adsorbed species during the catalytic reaction and (b) SFG spectra of cyclohexene hydrogenation to cyclohexane and dehydrogenation to benzene. These two reactions occur simultaneously in excess hydrogen of about 10 Torr and 1.5 Torr of hydrocarbon. SFG vibration spectra reveals that the presence of three different species on the surface in this reactant mixture, 1,4-, 1,3-cyclohexadienes and $\pi$-allyl $\mathrm{c}-\mathrm{C}_{6} \mathrm{H}_{9}$, that are reaction intermediates. Adapted with permission from ${ }^{127}$. Copyright 2004 American Chemical Society.

Figure 15. Time-resolved FT-IR spectroscopy of ethylene hydrogenation over supported Pt nanoparticles (1 atm, $323 \mathrm{~K}$ ). On the left, panel (a) shows time resolved spectra of transient surface ethyl and associated decay kinetics (panel (b)). On the right, panel (c) shows time resolved spectral traces of ethane and associated growth kinetics (panel (d)). Adapted with permission from ref 63. Copyright 2005 American Chemical Society.

Figure 16. Time-resolved FT-IR monitoring of propylene hydrogenation over Pt nanoparticles supported on mesoporous silica SBA-15 (1 atm, $383 \mathrm{~K})$. Spectra of transient surface propyl intermediate, and of propane product inside the nanopores and upon release into the gas phase are shown. Adapted with permission from ref 64 . Copyright 2007 American Chemical Society.

Figure 17. SFG vibrational spectra of poly-HEMA. SFG spectra of poly(HEMA) surfaces (a) at the water/polymer interface, (b) in hydrated state, and (c) dehydrated state. (d) Schematic showing the change of molecular structure of poly(HEMA) during dehydration detected by SFG at water/poly(HEMA) interface. Adapted with permission from ref 69. Copyright 1999 American Chemical Society. 
Figure 18. (a) Schematic of surface modifying end groups (SMEs) and (b) selfassembling monolayer end-groups (SAMEs) that are covalently bonded to the polymer during synthesis can also be used to modify the surface composition.

Figure 19. (a) The change of orientation of the $\mathrm{LK}_{14}$ (Leucine-Lysine) peptide, and (b) SFG studies of the hydrophobic side (Leucine side) of the peptide adsorbs preferably on the polystyrene surface and the hydrophilic (Lysine side) of the peptide adsorbed at the silica interface. Adapted with permission from ref 66. Copyright 2006 American Chemical Society.

Figure 20. SFG vibrational spectra exhibiting three different types of water structures at the water-solid interfaces. Reprinted with permission from ref 73. Copyright 1993 The American Physical Society.

Figure 21. (a) Schemes of energy conversion from exothermic catalytic reaction or photon adsorption on metallic surfaces to hot electron flow on metal-semiconductor Schottky diode and (b) The energy band diagram of Schottky diode-based hot electron detection. Adapted with permission from ref 85. Copyright 2006 Wiley InterScience.

Figure 22. Schematic and photos of (a) $\mathrm{Pt} / \mathrm{TiO}_{2}$ diode and (b) $\mathrm{Pt} / \mathrm{GaN}$ diode.

Figure 23. Measurement of chemicurrent (hot electron flow) and turnover rate measured on $\mathrm{Pt} / \mathrm{TiO}_{2}$ under $\mathrm{CO}$ oxidation. Adapted with permission from ref 85. Copyright 2006 Wiley InterScience.

Figure 24. Photocurrent measured as a function of photonenergy on $\mathrm{Pt} / \mathrm{TiO}_{2}$ diode with the metal film thickness of $5 \mathrm{~nm}$. The red line represents the Fowler's law fit with fitting parameters of $\mathrm{n}=2$ and $\mathrm{E}_{\mathrm{SB}}=1.2 \mathrm{eV}$.

Figure 25: Binuclear $\mathrm{TiOCu}(\mathrm{I})$ charge-transfer chromophore covalently anchored on silica nanopore surface (MCM-41). Diffuse reflectance optical spectra of the metal-tometal charge-transfer absorption extending to $600 \mathrm{~nm}$, the $\mathrm{Cu}(\mathrm{I}) \mathrm{O}$ infrared bond mode of the $\mathrm{TiOCu}(\mathrm{I})$ unit, and X-ray absorption near edge structure spectrum (XANES) of the Ti center are shown. Adapted with permission from ref 114. Copyright 2005 American Chemical Society.

Figure 26: Photochemical splitting of $\mathrm{CO}_{2}$ to $\mathrm{CO}$ at excited $\mathrm{Zr}(\mathrm{IV}) \mathrm{OCu}(\mathrm{I})$ metal-to-metal charge-transfer site in silica nanopore (1 atm, $295 \mathrm{~K})$. In situ FT-IR spectra of carbon monoxide and water product of parent and isotopically labeled carbon dioxide are shown. Adapted with permission from ref 115. Copyright 2005 American Chemical Society.

Figure 27: All-inorganic photocatalyst for visible light water oxidation in silica nanopore consisting of a $\mathrm{TiOCr}(\mathrm{III})$ chromophore coupled to an $\mathrm{IrO}_{2}$ nanoclusterr catalyst. Diffuse reflectance optical spectra of the metal-to-metal charge-transfer absorption (red shaded area) and Fourier-transform extended X-ray absorption fine structure (FT-EXAFS) data of the unit are shown. The EXAFS data provide direct evidence for the oxo-bridged 
structure of the binuclear chromophore. The high resolution transmission electron microscope image (HR-TEM) shows the Ir oxide clusters inside the silica channels. Adapted with permission from ref 116 and 117. Copyright 2006 and 2008 American Chemical Society.

Figure 28: Oxygen evolution in liquid water driven by visible light $\mathrm{TiOCr}(\mathrm{III})-\mathrm{IrO}_{2}$ photocatalyst in MCM-41. (a) $\mathrm{O}_{2}$ evolution monitored by oxygen-selective electrode. (b) FT-Raman spectra of superoxide species formed upon water oxidation. (c) and (d) EPR spectra showing light-induced formation of $\mathrm{Ti}(\mathrm{III})$, and of superoxide interacting with the Ti acceptor site. Adapted with permission from ref 116. Copyright 2008 American Chemical Society.

Figure 29: Co oxide $\left(\mathrm{Co}_{3} \mathrm{O}_{4}\right)$ nanocluster catalyst in SBA-15 scaffold for efficient oxidation of water under mild conditions (pH 5.8, $295 \mathrm{~K}, 350 \mathrm{mV}$ overpotential). (a)-(c) TEM image of $\mathrm{Co}_{3} \mathrm{O}_{4}$ nanocluster in mesoporous silica (a) 4 wt\% loading; (b) 8 wt $\%$ loading; (c) bare $\mathrm{Co}_{3} \mathrm{O}_{4}$ cluster after removal of silica showing nanrod bundle structure. (d) EXAFS spectrum confirming spinel structure of catalyst. (e) and (f) Mass spectrometric monitoring of $\mathrm{O}_{2}$ yield in head space of aqueous suspension. The half reaction was driven by visible light using the $\mathrm{Ru}^{+2}(\mathrm{bpy})_{3} /$ persulfate sensitizer method. Adapted with permission from ref 33. Copyright 2006 Wiley InterScience. 
References

(1) Ertl, G.; Freund, H. J. Physics Today 1999, 52, 32-38.

(2) Campbell, C. T. Surface Science Reports 1997, 27, 1-111.

(3) Freund, H. J.; Kuhlenbeck, H.; Libuda, J.; Rupprechter, G.; Baumer, M.; Hamann, H. Topics in Catalysis 2001, 15, 201-209.

(4) Somorjai, G. A.; Park, J. Y. Journal of Chemical Physics 2008, 128, 182504

(5) Somorjai, G. A.; York, R. L.; Butcher, D.; Park, J. Y. Physical Chemistry Chemical Physics 2007, 9, 3500-3513.

(6) Osterlund, L.; Rasmussen, P. B.; Thostrup, P.; Laegsgaard, E.; Stensgaard, I.; Besenbacher, F. Physical Review Letters 2001, 86, 460-463.

(7) Stoltze, P.; Norskov, J. K. Physical Review Letters 1985, 55, 2502-2505.

(8) Borodko, Y.; Humphrey, S. M.; Tilley, T. D.; Frei, H.; Somorjai, G. A. Journal of Physical Chemistry C 2007, 111, 6288-6295.

(9) Wasylenko, W.; Frei, H. Physical Chemistry Chemical Physics 2007, 9, 5497-5502.

(10) Somorjai, G. A.; Park, J. Y. Topics in Catalysis 2008, 49, 126-135.

(11) Tsung, C. K.; Kuhn, J. N.; Huang, W. Y.; Aliaga, C.; Hung, L. I.; Somorjai, G. A.; Yang, P. D. Journal of the American Chemical Society 2009, 131, 5816-5822.

(12) Grass, M. E.; Yue, Y.; Habas, S. E.; Rioux, R. M.; Teall, C. I.; Yang, P.; Somorjai, G. A. Journal of Physical Chemistry C 2008, 112, 4797-4804.

(13) Mermut, O.; York, R. L.; Phillips, D. C.; McCrea, K. R.; Ward, R. S.; Somorjai, G. A. Biointerphases 2006, 1, P5-P11.

(14) Clark, J. H. Green Chemistry 1999, 1, 1-8.

(15) Somorjai, G. A.; Park, J. Y.; Angewandte Chemie-International Edition 2008, p 9212-9228.

(16) Zaera, F. Journal of Physical Chemistry B 2002, 106, 4043-4052.

(17) Bratlie, K. M.; Lee, H.; Komvopoulos, K.; Yang, P.; Somorjai, G. A. Nano Letters 2007, 7, 3097-3101.

(18) Dahl, S.; Taylor, P. A.; Tornqvist, E.; Chorkendorff, I. Journal of Catalysis 1998, 178, 679-686.

(19) Logadottir, A.; Rod, T. H.; Norskov, J. K.; Hammer, B.; Dahl, S.; Jacobsen, C. J. H. Journal of Catalysis 2001, 197, 229-231.

(20) Berlowitz, P. J.; Peden, C. H. F.; Goodman, D. W. Journal of Physical Chemistry 1988, 92, 5213-5221.

(21) Eiswirth, M.; Moller, P.; Wetzl, K.; Imbihl, R.; Ertl, G. Journal of Chemical Physics 1989, 90, 510-521.

(22) Montano, M.; Bratlie, K.; Salmeron, M.; Somorjai, G. A. Journal of the American Chemical Society 2006, 128, 13229-13234.

(23) Guo, X. C.; Madix, R. J. Journal of Catalysis 1995, 155, 336-344.

(24) Pallassana, V.; Neurock, M. Journal of Catalysis 2000, 191, 301-317.

(25) Best, R. J.; Russell, W. W. Journal of the American Chemical Society 1954, 76, 838-842. 
(26) Somorjai, G. A.; Tao, F.; Park, J. Y. Topics in Catalysis 2008, 47, 1-14.

(27) Zhang, Y.; Grass, M. E.; Habas, S. E.; Tao, F.; Zhang, T.; Yang, P.; Somorjai, G. A. Journal of Physical Chemistry C 2007, 111, 12243-12253.

(28) Lee, H.; Habas, S. E.; Kweskin, S.; Butcher, D.; Somorjai, G. A.; Yang, P. D. Angewandte Chemie-International Edition 2006, 45, 7824-7828.

(29) Zhang, Y. W.; Grass, M. E.; Kuhn, J. N.; Tao, F.; Habas, S. E.; Huang, W. Y.; Yang, P. D.; Somorjai, G. A. Journal of the American Chemical Society 2008, 130, 5868.

(30) Park, J. Y.; Zhang, Y.; Grass, M.; Zhang, T.; Somorjai, G. A. Nano Letters 2008, 8, 673 -677.

(31) Song, H.; Kim, F.; Connor, S.; Somorjai, G. A.; Yang, P. D. Journal of Physical Chemistry B 2005, 109, 188-193.

(32) Song, H.; Rioux, R. M.; Hoefelmeyer, J. D.; Komor, R.; Niesz, K.; Grass, M.; Yang, P. D.; Somorjai, G. A. Journal of the American Chemical Society 2006, 128, 3027-3037.

(33) Jiao, F.; Frei, H. Angewandte Chemie-International Edition 2009, 48, 1841-1844.

(34) Niu, Y. H.; Yeung, L. K.; Crooks, R. M. Journal of the American Chemical Society 2001, 123, 6840-6846.

(35) Huang, W.; Kuhn, J. N.; Tsung, C. K.; Zhang, Y.; Habas, S. E.; Yang, P.; Somorjai, G. A. Nano Letters 2008, 8, 2027-2034.

(36) Somorjai, G. A.; Rioux, R. M. Catalysis Today 2005, 100, 201-215.

(37) Kliewer, C. J.; Bieri, M.; Somorjai, G. A. Journal of the American Chemical Society 2009, 131, 9958-9966.

(38) Kuhn, J. N.; Huang, W. Y.; Tsung, C. K.; Zhang, Y. W.; Somorjai, G. A. Journal of the American Chemical Society 2008, 130, 14026.

(39) Salmeron, M.; Schlogl, R. Surface Science Reports 2008, 63, 169-199.

(40) Tao, F.; Grass, M. E.; Zhang, Y. W.; Butcher, D. R.; Renzas, J. R.; Liu, Z.; Chung, J. Y.; Mun, B. S.; Salmeron, M.; Somorjai, G. A. Science 2008, 322, 932-934.

(41) Tang, D. C.; Hwang, K. S.; Salmeron, M.; Somorjai, G. A. Journal of Physical Chemistry B 2004, 108, 13300-13306.

(42) Rider, K. B.; Hwang, K. S.; Salmeron, M.; Somorjai, G. A. Journal of the American Chemical Society 2002, 124, 5588-5593.

(43) Su, X. C.; Jensen, J.; Yang, M. X.; Salmeron, M. B.; Shen, Y. R.; Somorjai, G. A. Faraday Discussions 1996, 105, 263-274.

(44) Bratlie, K. M.; Montano, M. O.; Flores, L. D.; Paajanen, M.; Somorjai, G. A. Journal of the American Chemical Society 2006, 128, 12810-12816.

(45) Ogletree, D. F.; Bluhm, H.; Lebedev, G.; Fadley, C. S.; Hussain, Z.; Salmeron, M. Review of Scientific Instruments 2002, 73, 3872-3877.

(46) Montano, M.; Salmeron, M.; Somorjai, G. A. Surface Science 2006, $600,1809-1816$.

(47) Montano, M.; Tang, D. C.; Somorjai, G. A. Catalysis Letters 2006, 107, 131-141.

(48) Bratlie, K. M.; Komvopoulos, K.; Somorjai, G. A. Journal of Physical Chemistry C 2008, 112, 11865-11868. 
(49) Longwitz, S. R.; Schnadt, J.; Vestergaard, E. K.; Vang, R. T.; Laegsgaard, E.; Stensgaard, I.; Brune, H.; Besenbacher, F. Journal of Physical Chemistry B 2004, 108, 14497-14502.

(50) Shen, Y. R. Nature 1989, 337, 519-525.

(51) Shen, Y. R. Annual Review of Physical Chemistry 1989, 40, 327-350.

(52) Zhang, D.; Gutow, J.; Eisenthal, K. B. Journal of Physical Chemistry 1994, 98, $13729-13734$.

(53) Conboy, J. C.; Messmer, M. C.; Richmond, G. L. Journal of Physical Chemistry 1996, 100, 7617-7622.

(54) Chen, Z.; Gracias, D. H.; Somorjai, G. A. Applied Physics B-Lasers and Optics 1999, 68, 549-557.

(55) Su, X. C.; Cremer, P. S.; Shen, Y. R.; Somorjai, G. A. Journal of the American Chemical Society 1997, 119, 3994-4000.

(56) Cremer, P. S.; Su, X. C.; Shen, Y. R.; Somorjai, G. A. Journal of the American Chemical Society 1996, 118, $2942-2949$.

(57) Bratlie, K. M.; Flores, L. D.; Somorjai, G. A. Surface Science 2005, 599, 93-106.

(58) Aliaga, C.; Park, J. Y.; Yamada, Y.; Lee, H. S.; Tsung, C. K.; Yang, P. D.; Somorjai, G. A. Journal of Physical Chemistry C 2009, 113, 6150-6155.

(59) Kweskin, S. J.; Rioux, R. M.; Habas, S. E.; Komvopoulos, K.; Yang, P.; Somorjai, G. A. Journal of Physical Chemistry B 2006, 110, 15920-15925.

(60) Vasenkov, S.; Frei, H. Journal of the American Chemical Society 1998, $120,4031-4032$.

(61) Yeom, Y. H.; Frei, H. Journal of Physical Chemistry B 2003, 107, 62866291.

(62) Ko, M. K.; Frei, H. Journal of Physical Chemistry B 2004, 108, $1805-$ 1808.

(63) Wasylenko, W.; Frei, H. Journal of Physical Chemistry B 2005, 109, 16873-16878.

(64) Wasylenko, W.; Frei, H. Journal of Physical Chemistry C 2007, 111, 9884-9890.

(65) Kim, J.; Somorjai, G. A. Journal of the American Chemical Society 2003, 125, 3150-3158.

(66) Mermut, O.; Phillips, D. C.; York, R. L.; McCrea, K. R.; Ward, R. S.; Somorjai, G. A. Journal of the American Chemical Society 2006, 128, 3598-3607.

(67) Sauerbrey, G. Zeitschrift Fur Physik 1959, 155, 206-222.

(68) Kim, J.; Koffas, T. S.; Lawrence, C. C.; Somorjai, G. A. Langmuir 2004, 20, 4640-4646.

(69) Chen, Q.; Zhang, D.; Somorjai, G.; Bertozzi, C. R. Journal of the American Chemical Society 1999, 121, 446-447.

(70) Denyer, S. P.; Stewart, G.; Elsevier Sci Ltd: 1998, p 261-268.

(71) Patel, J. D.; Ebert, M.; Stokes, K.; Ward, R.; Anderson, J. M. Journal of Biomaterials Science-Polymer Edition 2003, 14, 279-295.

(72) Senaratne, W.; Andruzzi, L.; Ober, C. K. Biomacromolecules 2005, 6, 2427-2448. 
(73) Du, Q.; Superfine, R.; Freysz, E.; Shen, Y. R. Physical Review Letters 1993, 70, 2313-2316.

(74) Baldelli, S.; Mailhot, G.; Ross, P. N.; Somorjai, G. A. Journal of the American Chemical Society 2001, 123, 7697-7702.

(75) Hill, J.; Nelson, E.; Tilman, D.; Polasky, S.; Tiffany, D. Proceedings of the National Academy of Sciences of the United States of America 2006, 103, 1120611210.

(76) Crabtree, G. W.; Lewis, N. S. Physics Today 2007, 60, 37-42.

(77) Gratzel, M. Inorganic Chemistry 2005, 44, 6841-6851.

(78) Kamat, P. V. Journal of Physical Chemistry C 2007, 111, 2834-2860.

(79) Lewis, N. S.; Nocera, D. G. Proceedings of the National Academy of Sciences of the United States of America 2006, 103, 15729-15735.

(80) Gadzuk, J. W. Journal of Physical Chemistry B 2002, 106, 8265-8270.

(81) Huang, Y.; Wodtke, A. M.; Hou, H.; Rettner, C. T.; Auerbach, D. J. Physical Review Letters 2000, 84, 2985-2988.

(82) Kasemo, B.; Tornqvist, E.; Norskov, J. K.; Lundqvist, B. I. Surface Science 1979, 89, 554-565.

(83) Nienhaus, H. Surface Science Reports 2002, 45, 3-78.

(84) Ji, X. Z.; Zuppero, A.; Gidwani, J. M.; Somorjai, G. A. Journal of the American Chemical Society 2005, 127, 5792-5793.

(85) Park, J. Y.; Somorjai, G. A. Chemphyschem 2006, 7, 1409-1413.

(86) Park, J. Y.; Renzas, J. R.; Hsu, B. B.; Somorjai, G. A. Journal of Physical Chemistry C 2007, 111, 15331-15336.

(87) Persson, M.; Hellsing, B. Physical Review Letters 1982, 49, 662-665.

(88) Tully, J. C. Annual Review of Physical Chemistry 2000, 51, 153-178.

(89) Maximoff, S. N.; Head-Gordon, M. P. Proceedings of the National Academy of Sciences of the United States of America 2009, 106, 11460-11465.

(90) Mizielinski, M. S.; Bird, D. M.; Persson, M.; Holloway, S. Journal of Chemical Physics 2005, 122, 084710.

(91) Hohlfeld, J.; Wellershoff, S. S.; Gudde, J.; Conrad, U.; Jahnke, V.; Matthias, E. Chemical Physics 2000, 251, 237-258.

(92) Inouye, H.; Tanaka, K.; Tanahashi, I.; Hirao, K. Physical Review B 1998, 57, 11334-11340.

(93) Park, J. Y.; Lee, H.; Renzas, J. R.; Zhang, Y. W.; Somorjai, G. A. Nano Letters 2008, 8, 2388-2392.

(94) Park, J. Y.; Somorjai, G. A. Journal of Vacuum Science and Technology B 2006, 24, 1967-1971.

(95) McFarland, E. W.; Tang, J. Nature 2003, 421, 616-618.

(96) Fowler, R. H. Physical Review 1931, 38, 45-56.

(97) Stuckless, J. T.; Moskovits, M. Physical Review B 1989, 40, 9997-9998.

(98) Fujishima, A.; Honda, K. Nature 1972, 238, 37.

(99) Wrighton, M. S.; Ellis, A. B.; Wolczanski, P. T.; Morse, D. L.; Abrahamson, H. B.; Ginley, D. S. Journal of the American Chemical Society 1976, 98, 2774-2779.

(100) Kudo, A.; Miseki, Y. Chemical Society Reviews 2009, 38, 253-278.

(101) Osterloh, F. E. Chemistry of Materials 2008, 20, 35-54. 
(102) Kato, H.; Asakura, K.; Kudo, A. Journal of the American Chemical Society 2003, 125, 3082-3089.

(103) Maeda, K.; Teramura, K.; Lu, D. L.; Takata, T.; Saito, N.; Inoue, Y.; Domen, K. Nature 2006, 440, 295-295.

(104) Khaselev, O.; Turner, J. A. Science 1998, 280, 425-427.

(105) Hemminger, J. C.; Carr, R.; Somorjai, G. A. Chemical Physics Letters $1978,57,100-104$. 637-638.

(106) Inoue, T.; Fujishima, A.; Konishi, S.; Honda, K. Nature 1979, 277,

(107) Fujiwara, H.; Hosokawa, H.; Murakoshi, K.; Wada, Y.; Yanagida, S. Langmuir 1998, 14, 5154-5159. 735-758.

(108) Linsebigler, A. L.; Lu, G. Q.; Yates, J. T. Chemical Reviews 1995, 95,

(109) Yoneyama, H. Catalysis Today 1997, 39, 169-175.

(110) Beck, J. S.; Vartuli, J. C.; Roth, W. J.; Leonowicz, M. E.; Kresge, C. T.; Schmitt, K. D.; Chu, C. T. W.; Olson, D. H.; Sheppard, E. W.; McCullen, S. B.; Higgins, J. B.; Schlenker, J. L. Journal of the American Chemical Society 1992, 114, 10834-10843.

(111) Zhao, D. Y.; Feng, J. L.; Huo, Q. S.; Melosh, N.; Fredrickson, G. H.; Chmelka, B. F.; Stucky, G. D. Science 1998, 279, 548-552.

(112) Anpo, M.; Yamashita, H.; Ikeue, K.; Fujii, Y.; Zhang, S. G.; Ichihashi, Y.; Park, D. R.; Suzuki, Y.; Koyano, K.; Tatsumi, T.; Elsevier Science Bv: 1998, p 327-332.

(113) Lin, W. Y.; Han, H. X.; Frei, H. Journal of Physical Chemistry B 2004, $108,18269-18273$.

4935.

(114) Lin, W. Y.; Frei, H. Journal of Physical Chemistry B 2005, 109, 4929-

(115) Lin, W. Y.; Frei, H. Journal of the American Chemical Society 2005, $127,1610-1611$.

16159.

(116) Han, H. X.; Frei, H. Journal of Physical Chemistry C 2008, 112, 16156-

(117) Nakamura, R.; Frei, H. Journal of the American Chemical Society 2006, 128, 10668-10669.

(118) Morris, N. D.; Suzuki, M.; Mallouk, T. E. Journal of Physical Chemistry A 2004, 108, 9115-9119.

(119) Trasatti, S. Electrochimica Acta 1984, 29, 1503-1512.

(120) Harriman, A.; Pickering, I. J.; Thomas, J. M.; Christensen, P. A. Journal of the Chemical Society-Faraday Transactions I 1988, 84, 2795-2806.

(121) Kanan, M. W.; Nocera, D. G. Science 2008, 321, 1072-1075.

(122) Geletii, Y. V.; Botar, B.; Koegerler, P.; Hillesheim, D. A.; Musaev, D. G.; Hill, C. L. Angewandte Chemie-International Edition 2008, 47, 3896-3899.

(123) Sartorel, A.; Carraro, M.; Scorrano, G.; De Zorzi, R.; Geremia, S.; McDaniel, N. D.; Bernhard, S.; Bonchio, M. Journal of the American Chemical Society 2008, 130, 5006. 8399.

(124) Han, H. X.; Frei, H. Journal of Physical Chemistry C 2008, 112, 8391- 
(125) Nakamura, R.; Okamoto, A.; Osawa, H.; Irie, H.; Hashimoto, K. Journal of the American Chemical Society 2007, 129, 9596.

(126) Somorjai, G. A. Topics in Catalysis 2008, 48, 1-7.

(127) Yang, M. C.; Chou, K. C.; Somorjai, G. A. Journal of Physical Chemistry B 2004, 108, 14766-14779. 


\section{Nanosciences}

Monodispersed nanoparticles 2D and 3D

Applications in Catalysis, Tribology, Polymers, Biointerfaces, Microelectronics, Energy Conversions, Environmental Chemistry, Electrochemistry, Corrosion

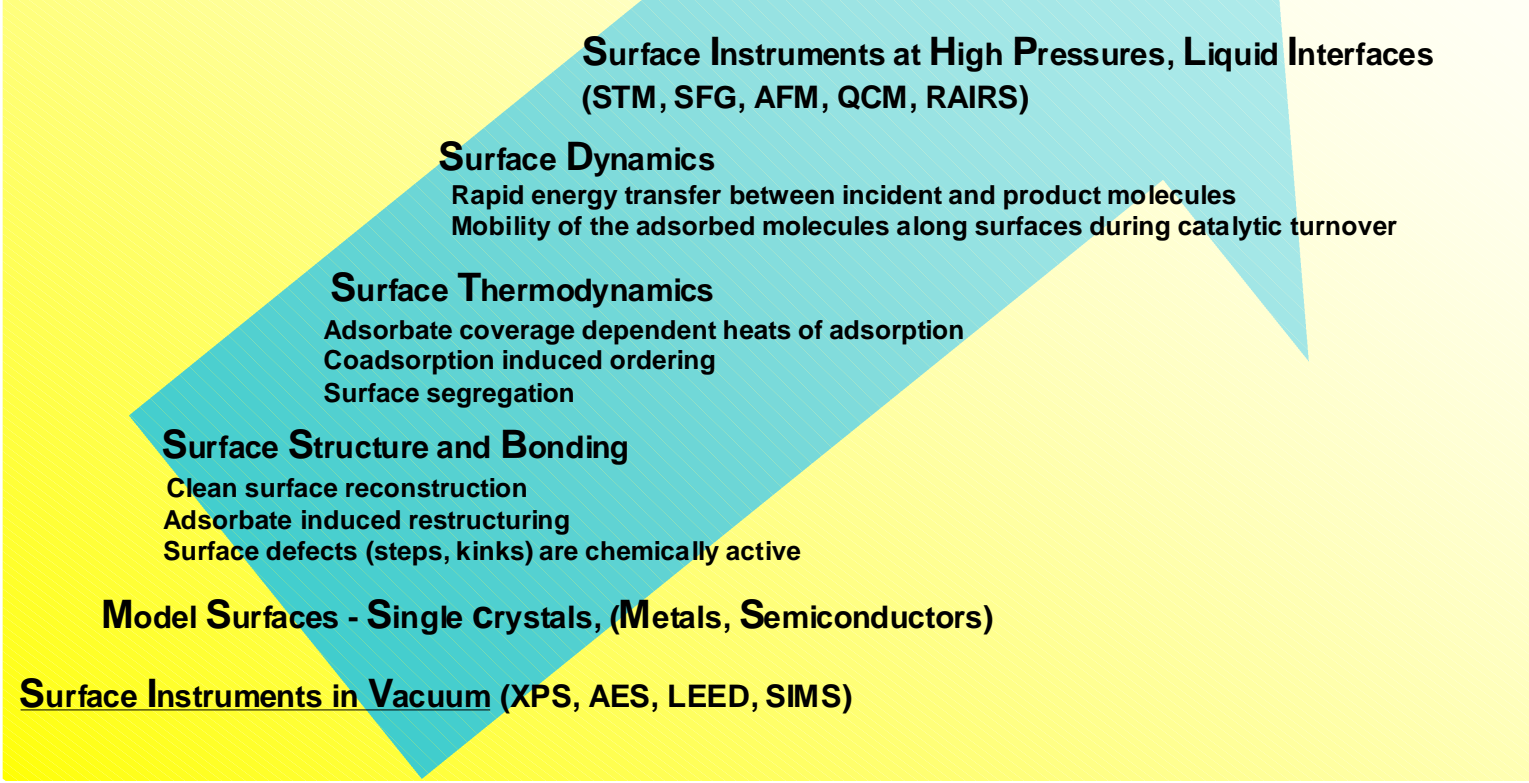

Figure 1. 


\begin{tabular}{|l|}
\hline \multicolumn{1}{|c|}{ Surface Science Techniques for Molecular-Level Studies } \\
\hline Surface Composition: \\
Auger electron spectroscopy, X-ray photoelectron spectroscopy, \\
Secondary ion mass spectrometry, lon scattering spectroscopy \\
\hline Surface structure: \\
Low-energy electron diffraction, Transmission electron microscopy, \\
Atom diffraction, Atomic force microscopy, Scanning tunneling \\
microscopy, Surface X-ray diffraction, X-ray absorption fine structure \\
\hline Surface electronic structure: \\
Second harmonic generation, Ultraviolet photoelectron spectroscopy, X-ray \\
emission spectroscopy, Scanning tunneling spectroscopy \\
\hline Surface vibration and reaction dynamics: \\
Electron energy loss spectroscopy, Helium atom scattering, IR \\
spectroscopy, Raman spectroscopy, Sum-frequency generation \\
spectroscopy, Molecular beam surface scattering \\
Surface thermodynamics: \\
Microcalorimetry, adsorption/desorption \\
\hline
\end{tabular}

Figure 2. 
(a)

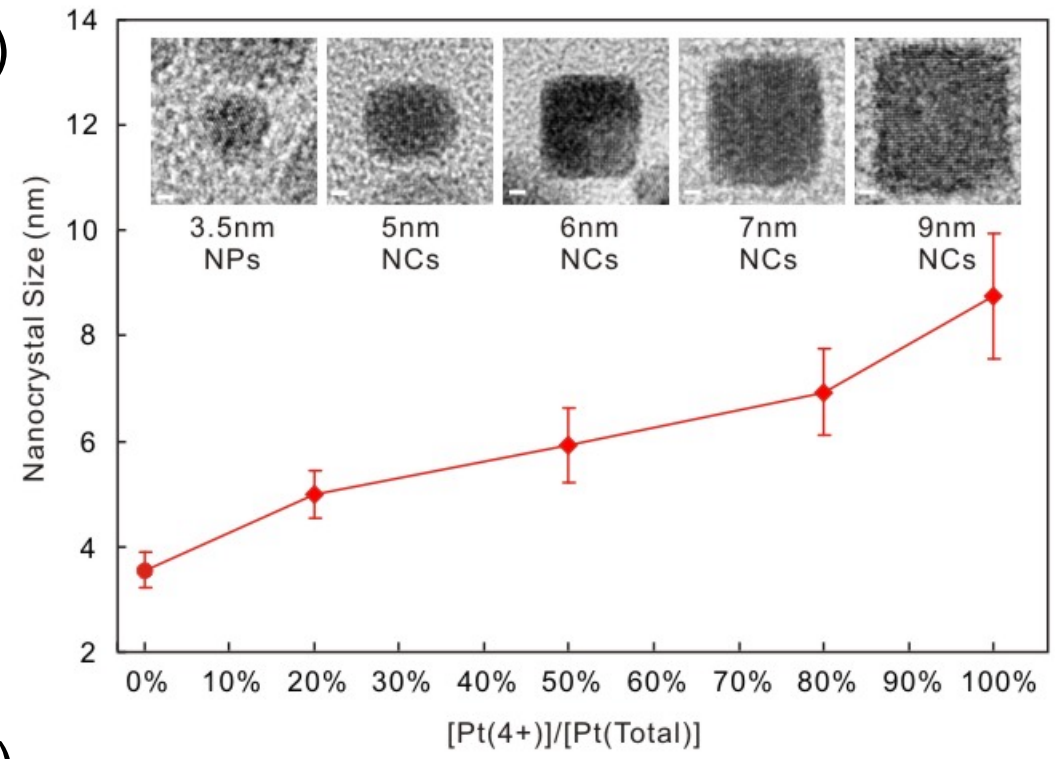

(b)

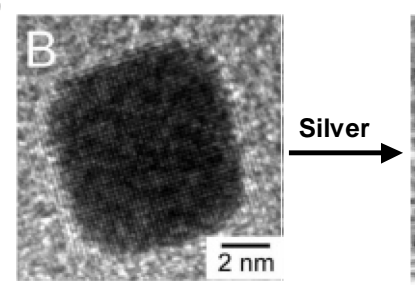

(c)

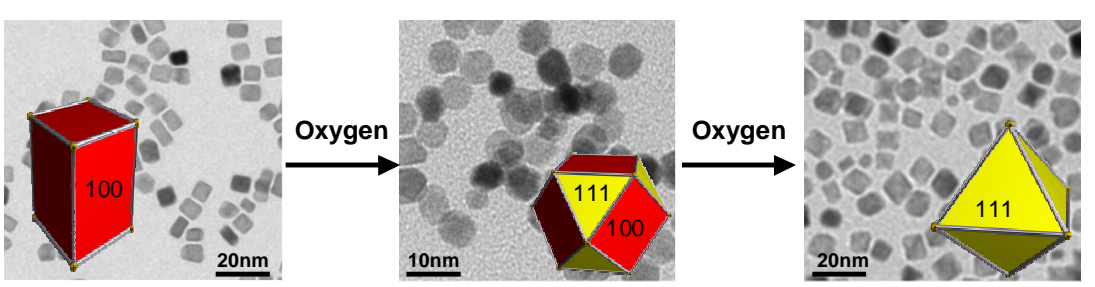

Figure 3. 
(a) Soft Contact Lens

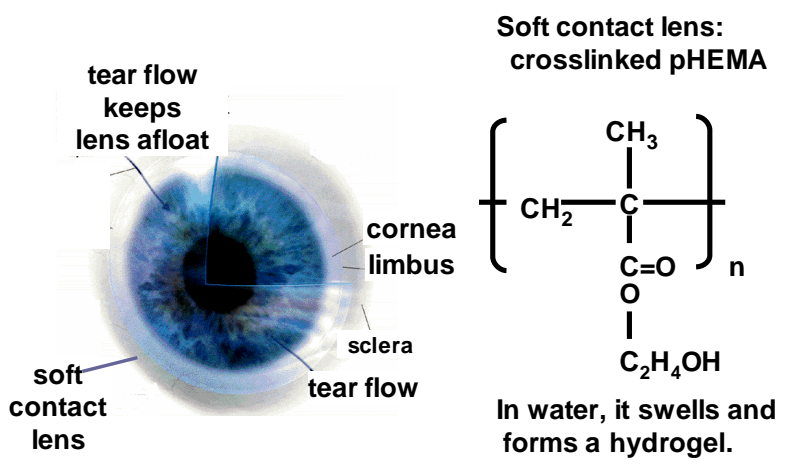

pHEMA = poly(2-hydroxyethyl methacrylate)

(c) Polyurethane Under Reversible Loading (Fatigue Test)

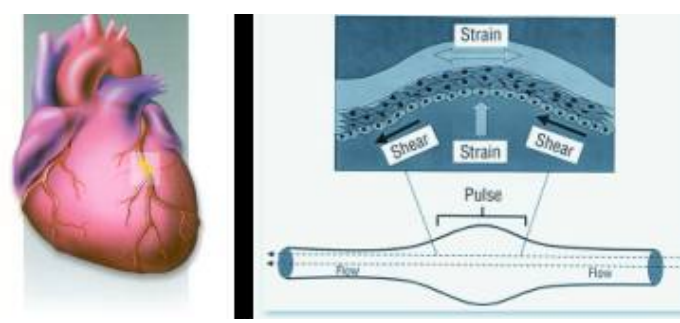

3.2 billion heart valve loading cycles in $\sim 80$ years of normal heart function. (b)

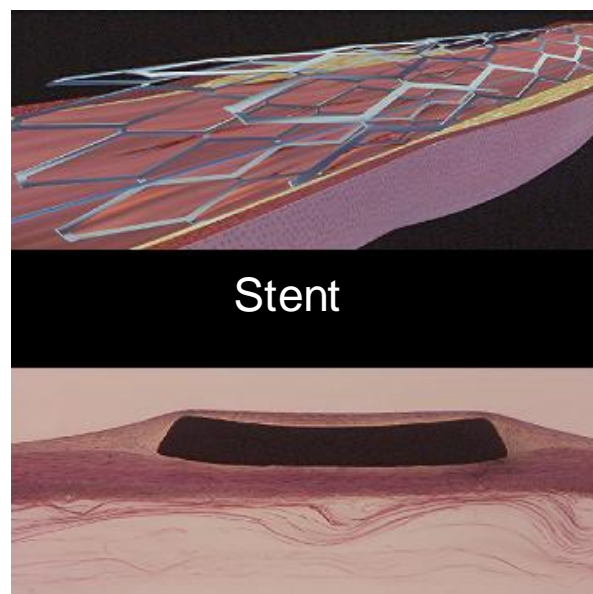

(d)

$$
\text { Prosthesis }
$$

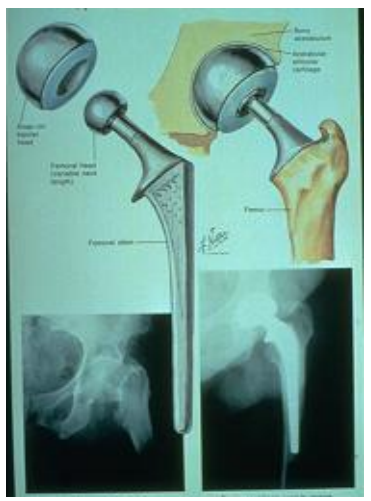

Figure 4. 


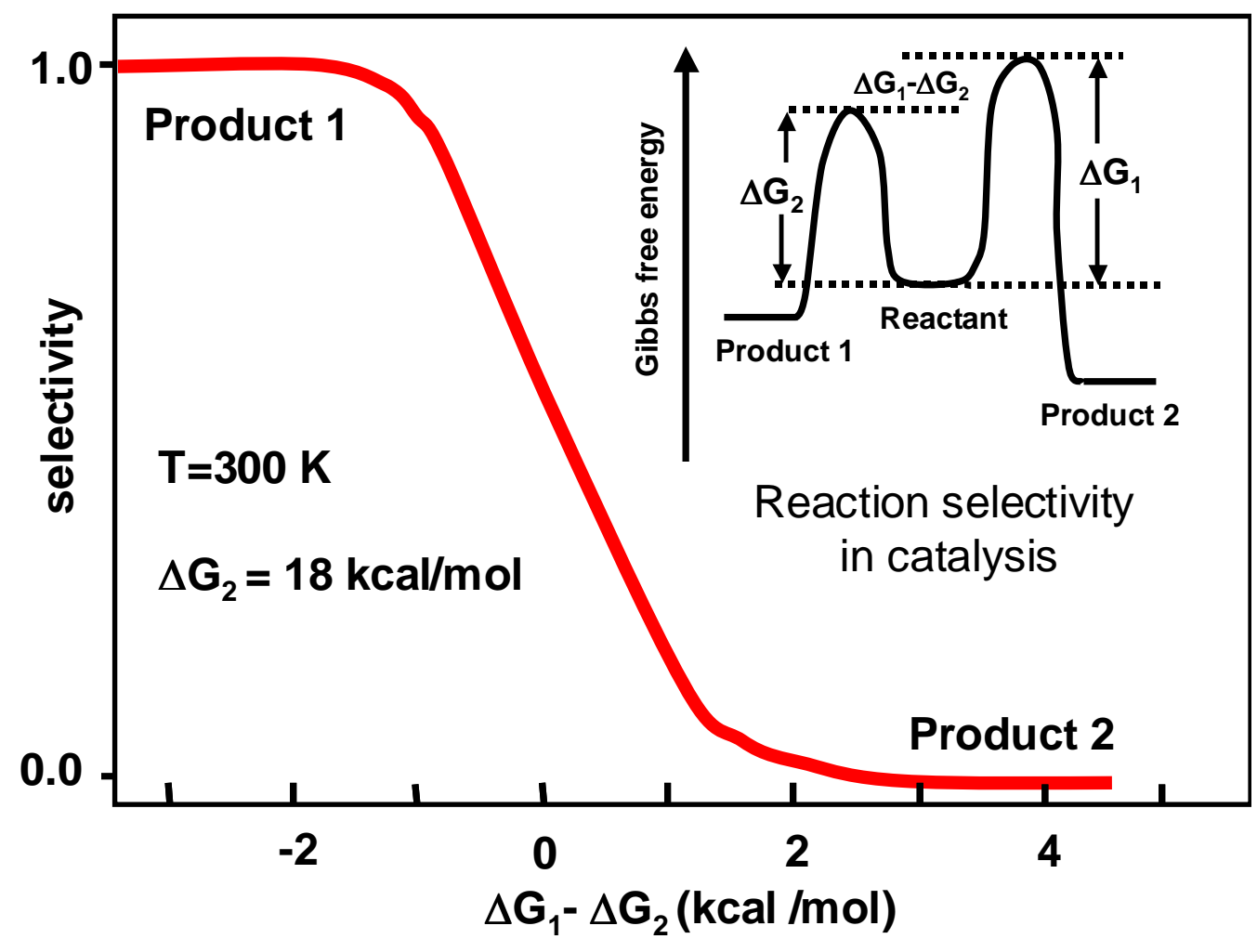

Figure 5. 


\section{$\mathrm{Rh}(\mathrm{acac})_{3}$ $+$ $\mathrm{Pt}(\mathrm{acac})_{2}$}

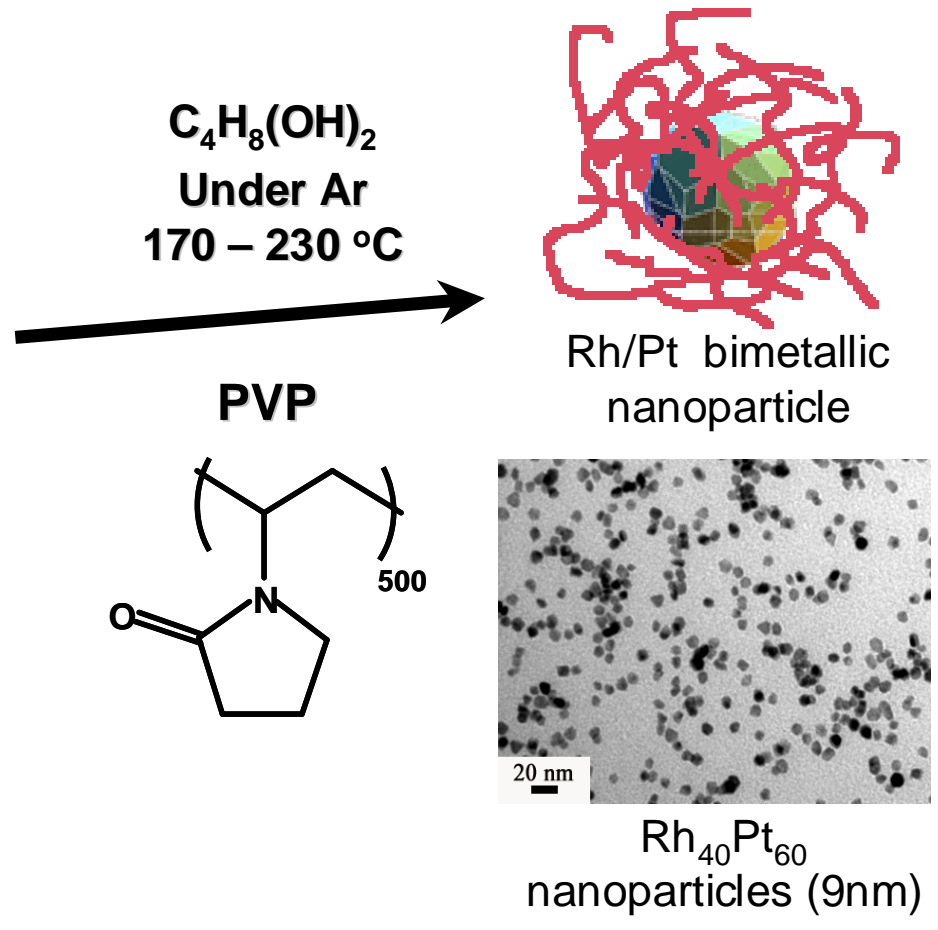

Figure 6. 


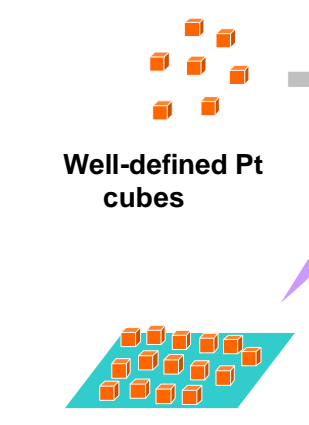

Monolayer of Pt cubes on water surface

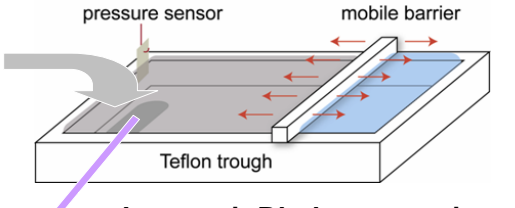

Langmuir-Blodgett experiment

\section{substrates}

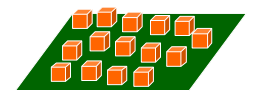

2D nanoparticle array (1-10nm, disordered)

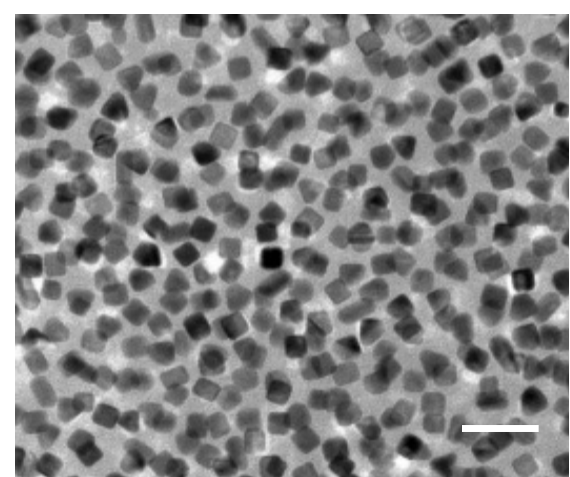

Figure 7. 

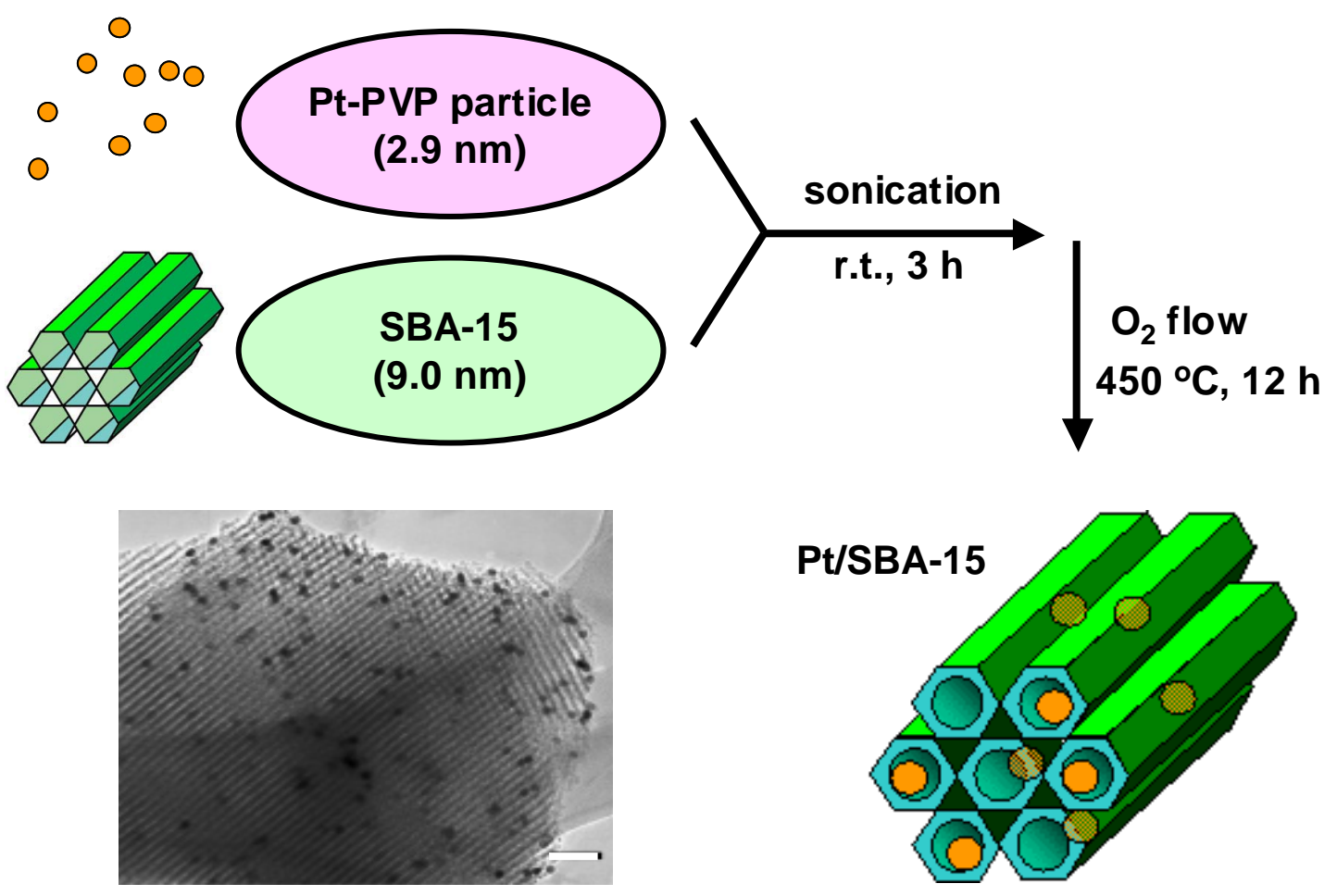

3D nanoparticle array

Figure 8. 
(a)

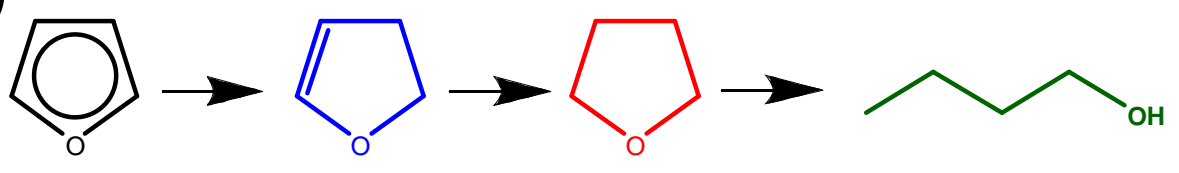

furan 2,3-dihydrofuran (DHF) tetrahydrofuran (THF) butanol

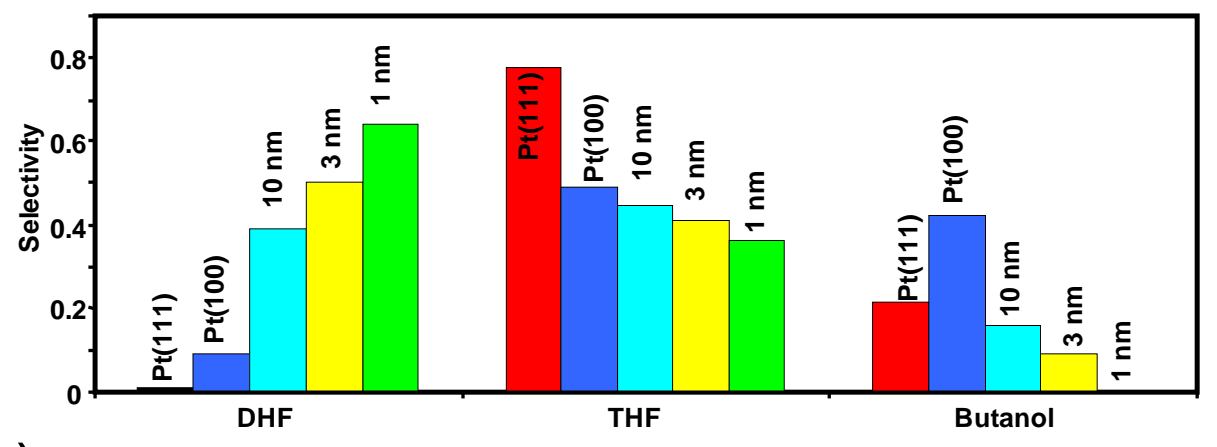

(b)

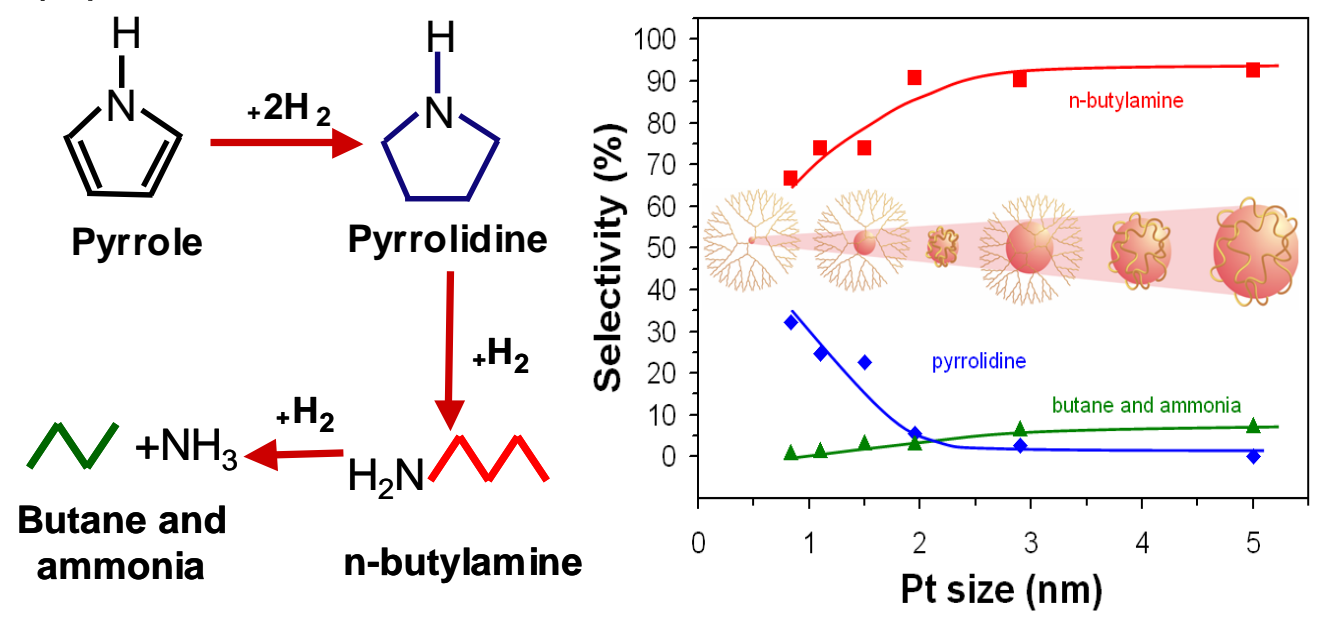

Figure 9. 
(a)
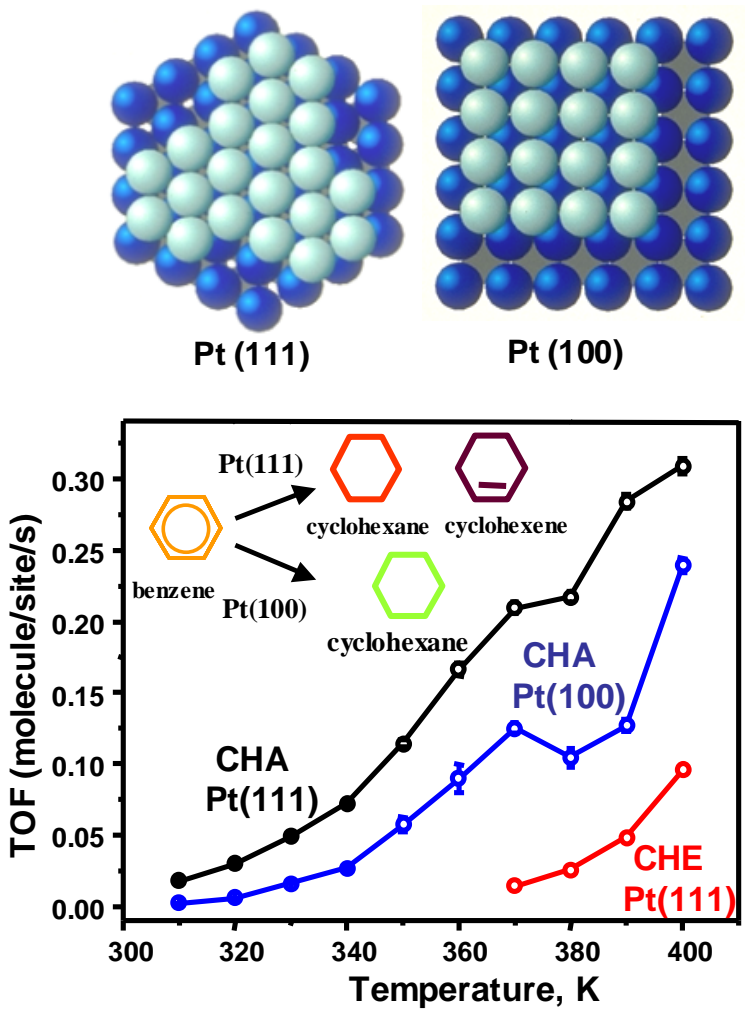

Pt (100) (b)

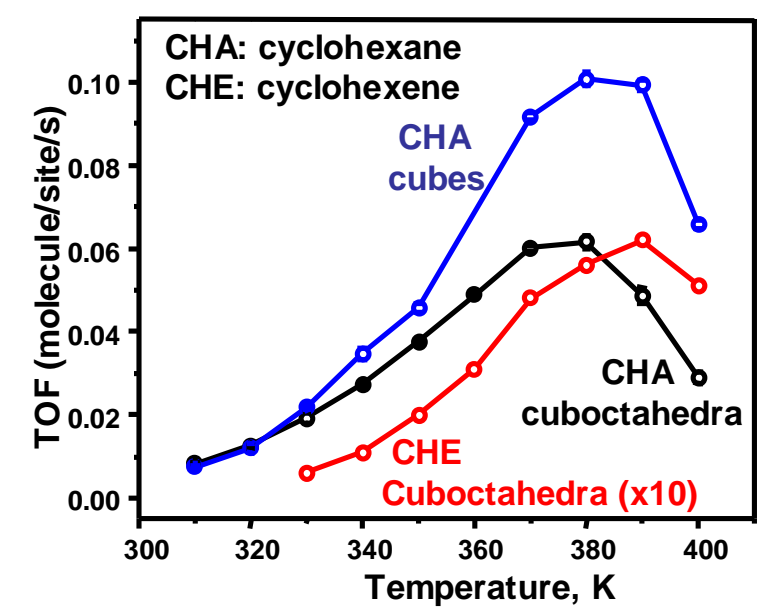

Figure 10. 


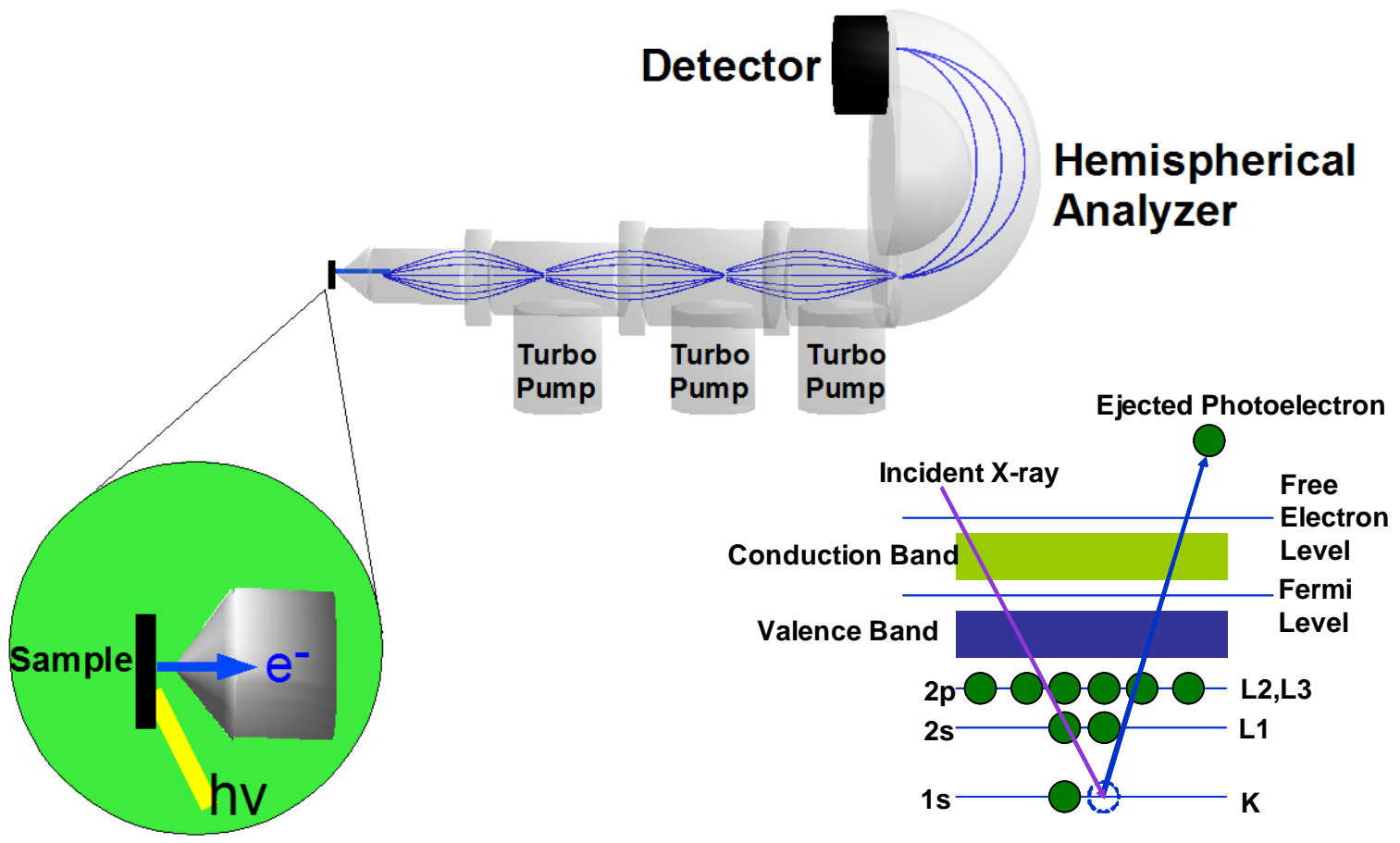

Figure 11. 

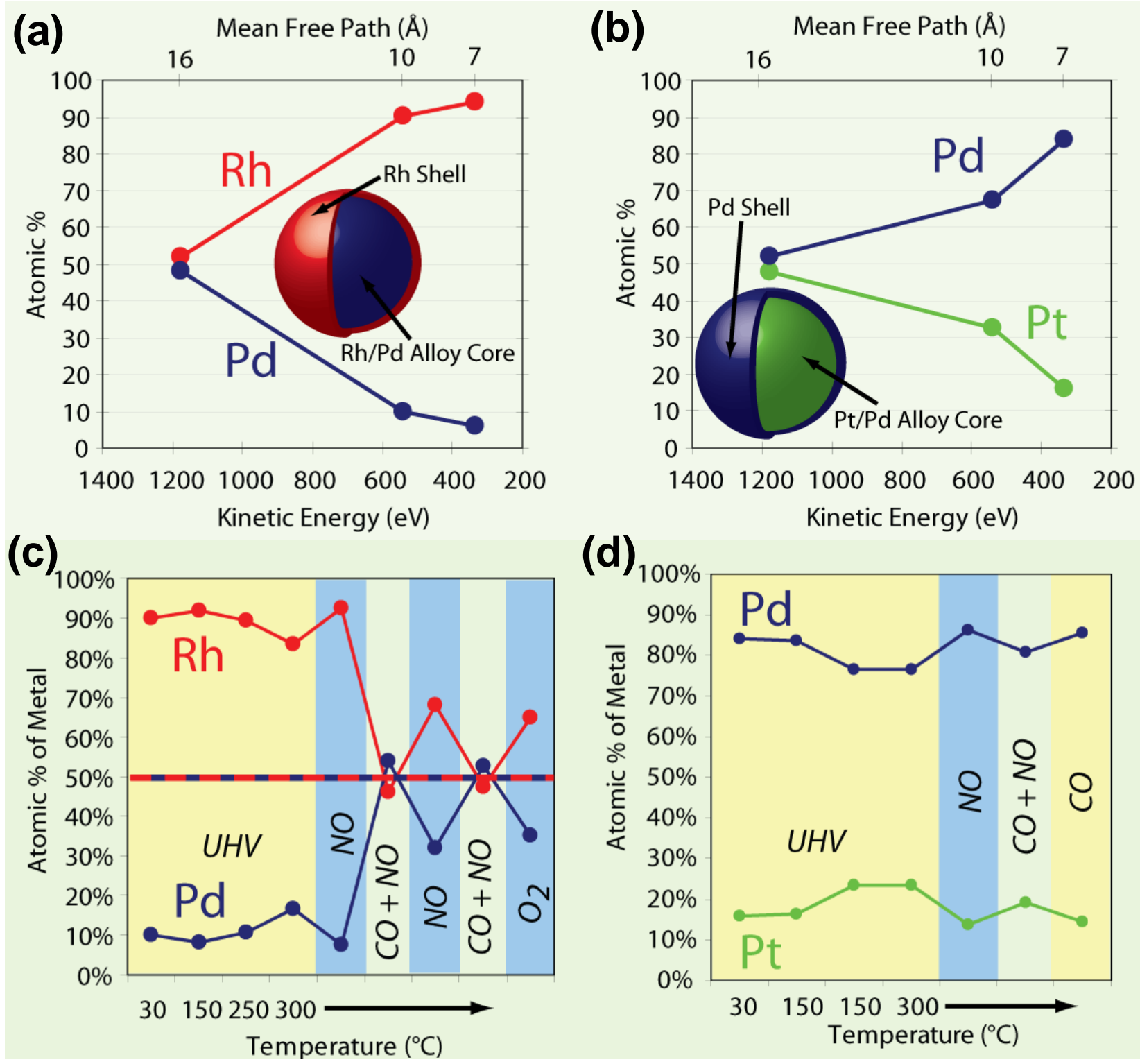

Figure 12. 
(a)

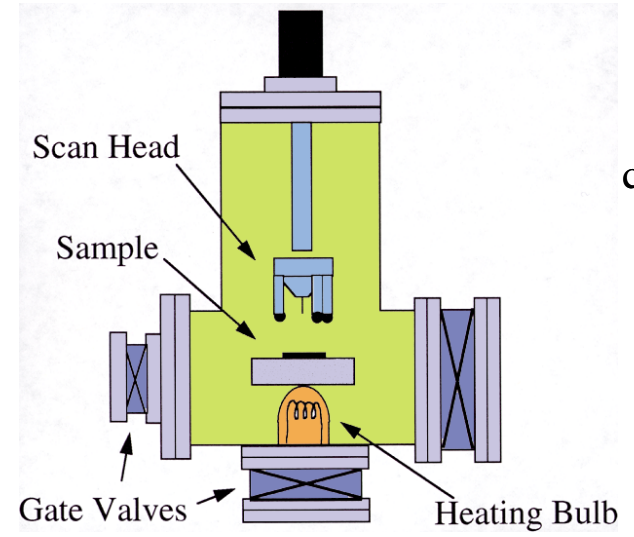

(b)

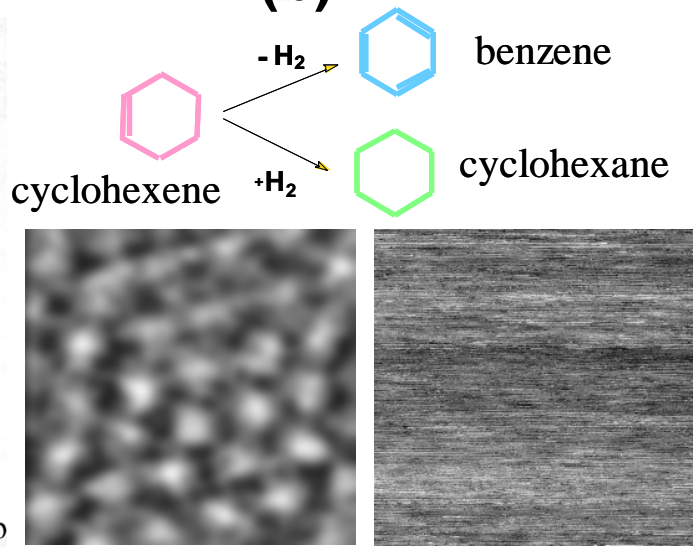

(c)

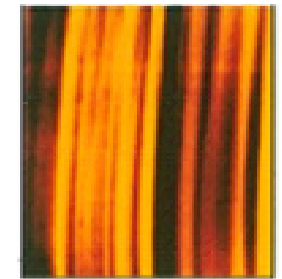

$73 \mathrm{~nm} \times 70 \mathrm{~nm}$
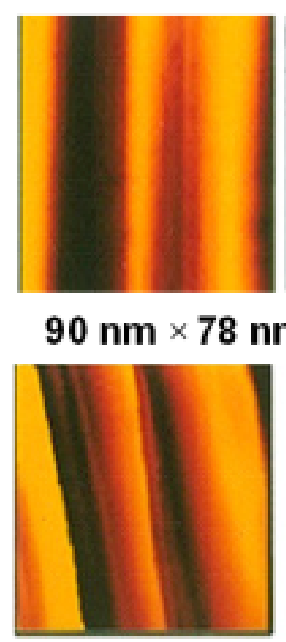

$77 \mathrm{~nm} \times 74 \mathrm{~nm}$

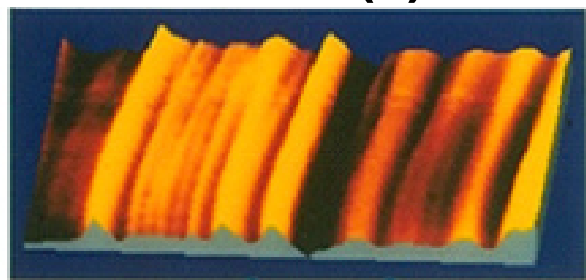

Hydrogen: $1.7 \mathrm{~atm}$.

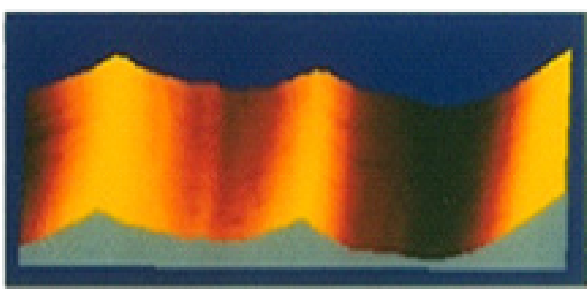

Oxygen: $1 \mathrm{~atm}$.

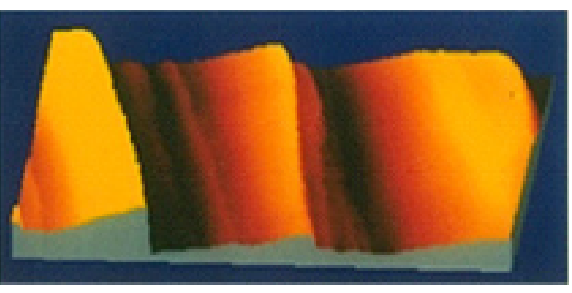

Carbon Monoxide: $1 \mathrm{~atm}$.

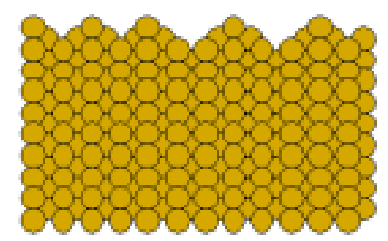

"nested" missingr ow reconstructions

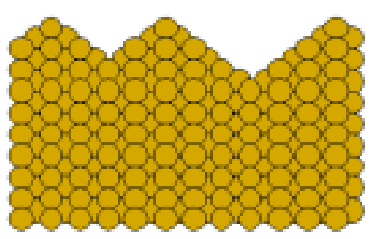

fcc (111) microfacets

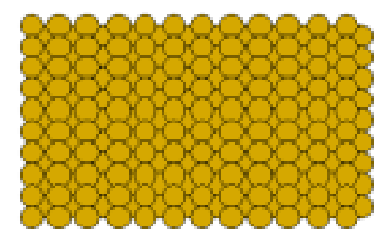

Unreconstr ucted (111) terraces separated by multiple height steps

Figure 13. 
(a)

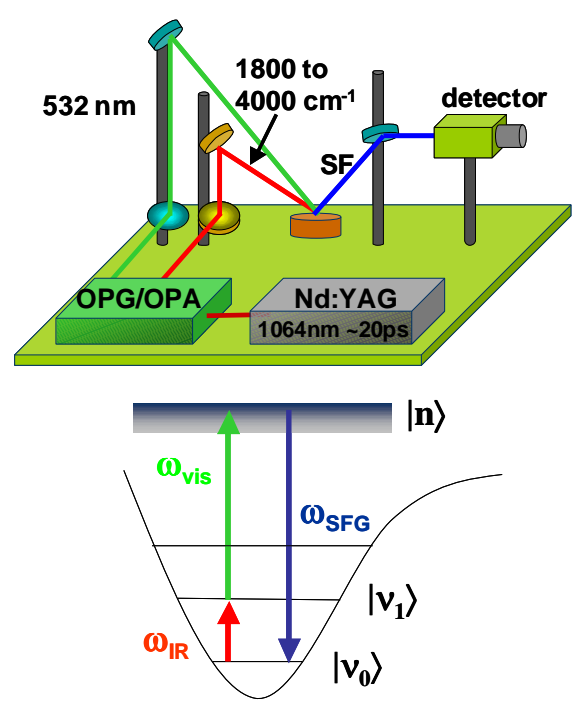

(b)

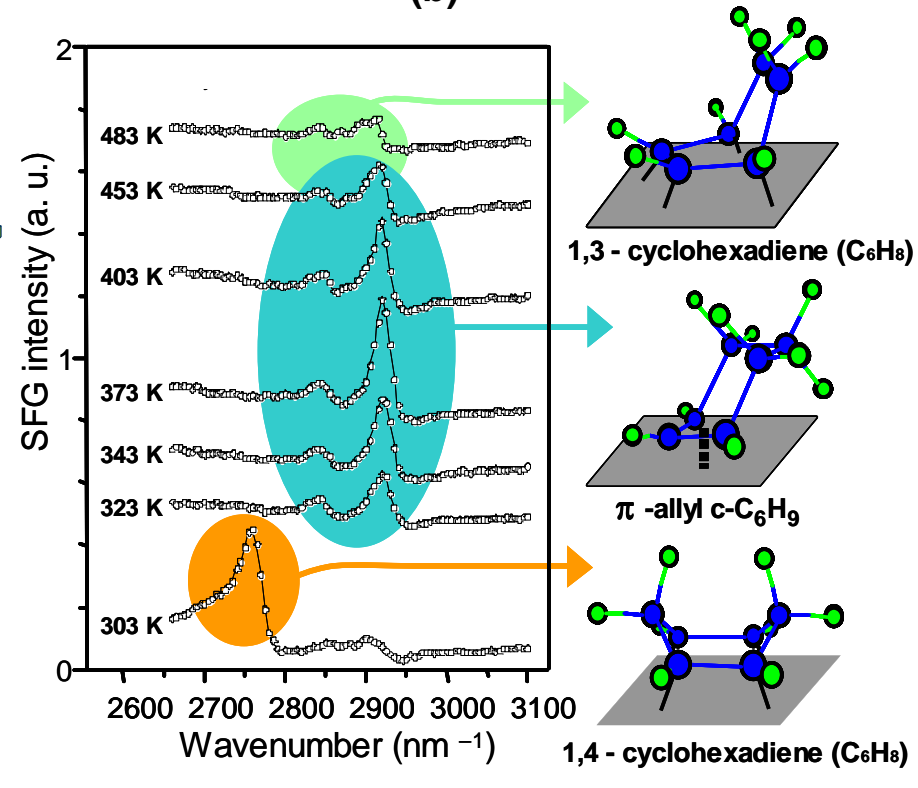

Figure 14. 

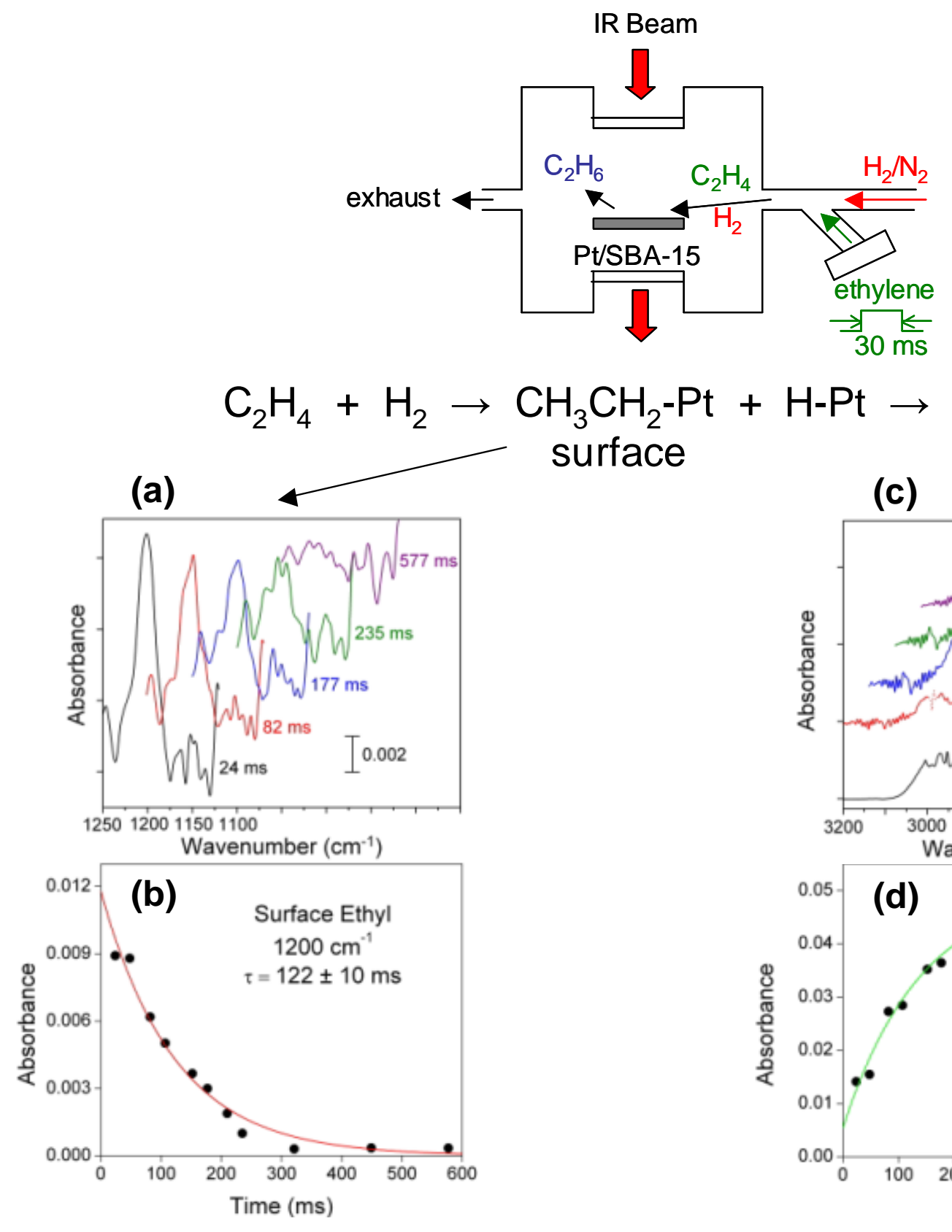


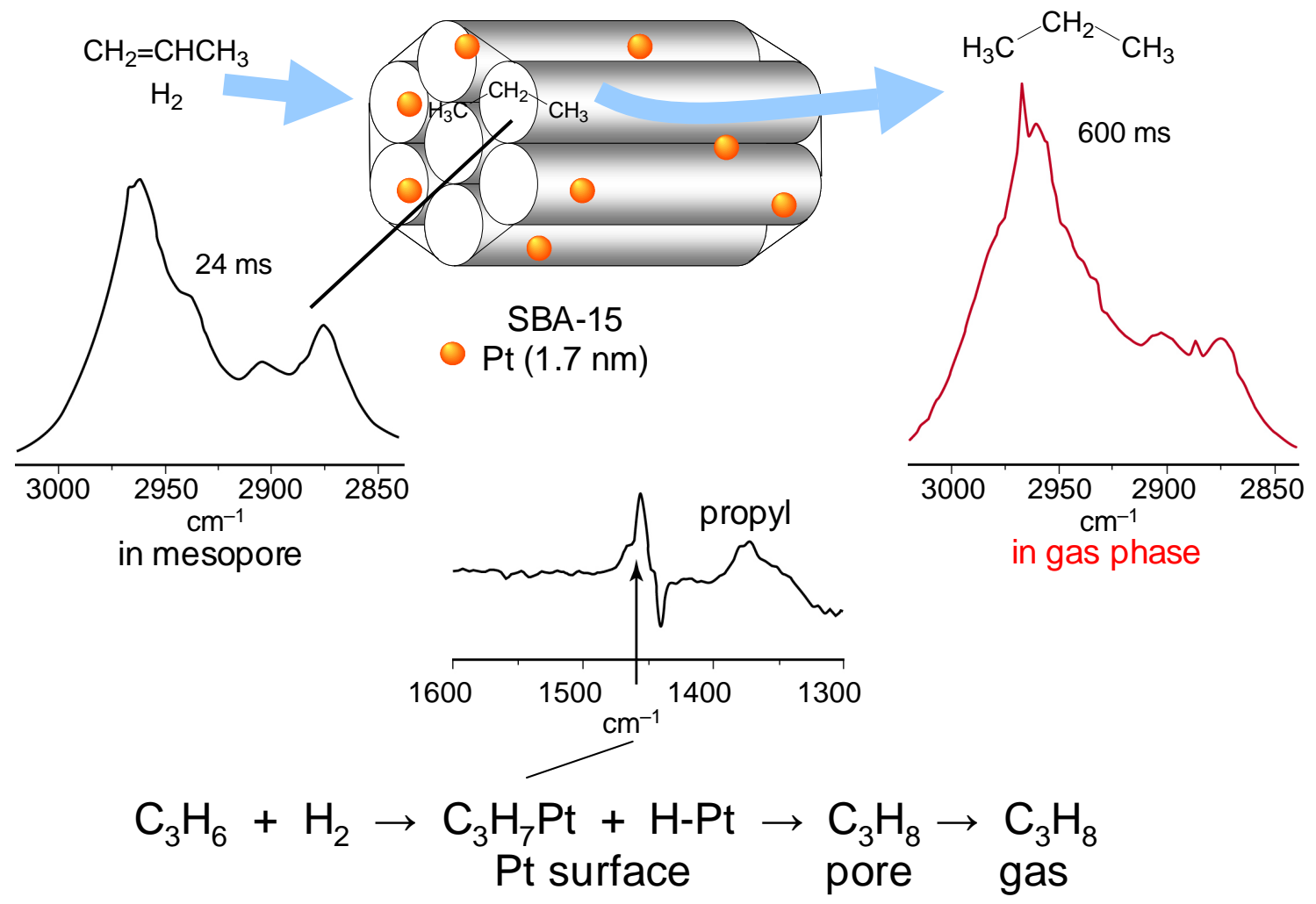

Figure 16. 
(a) hydroxyethyl methyl
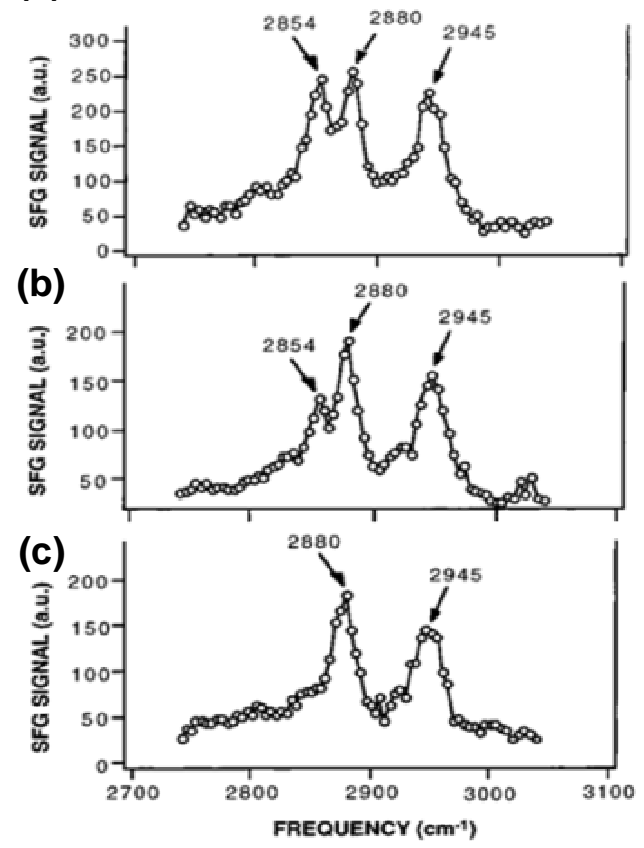

(d)
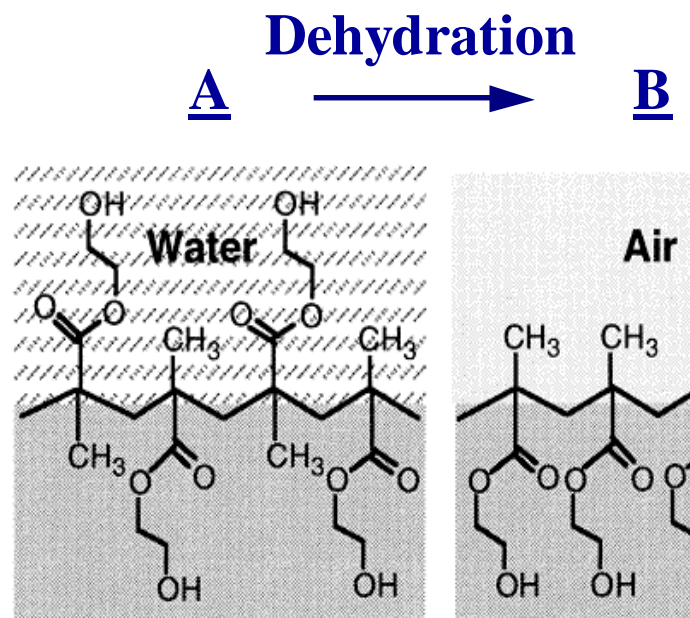

Hydrated state
Air

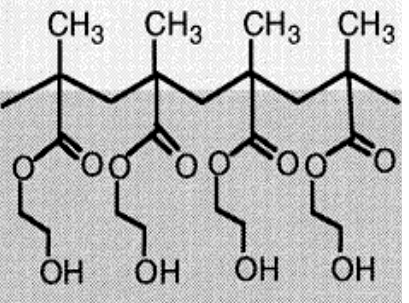

Dehydrated state

Figure 17. 
(a)

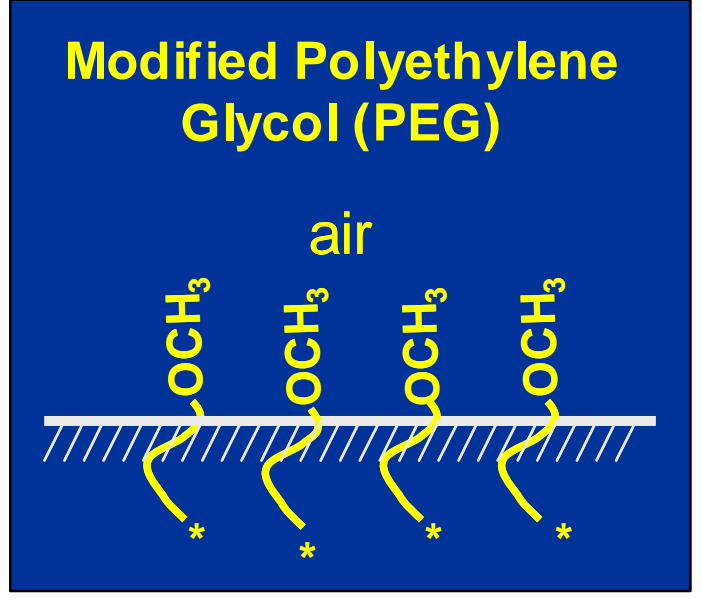

(b)

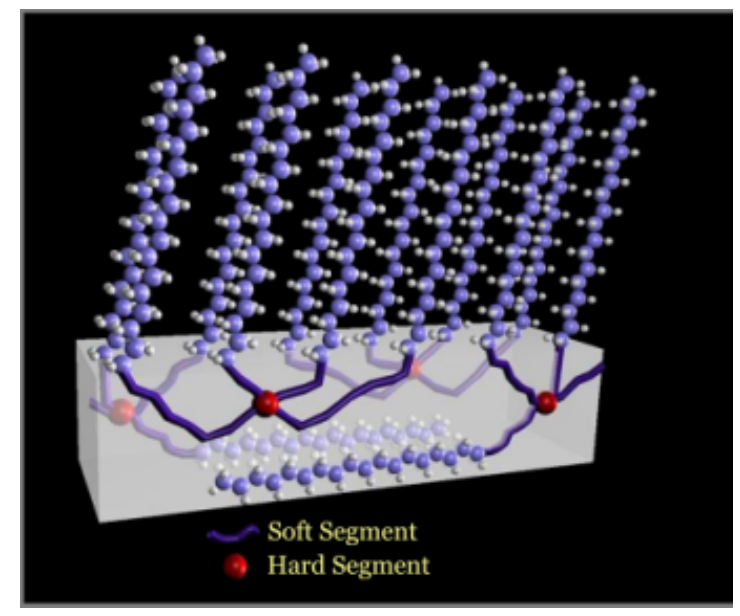

Figure 18. 
(a)

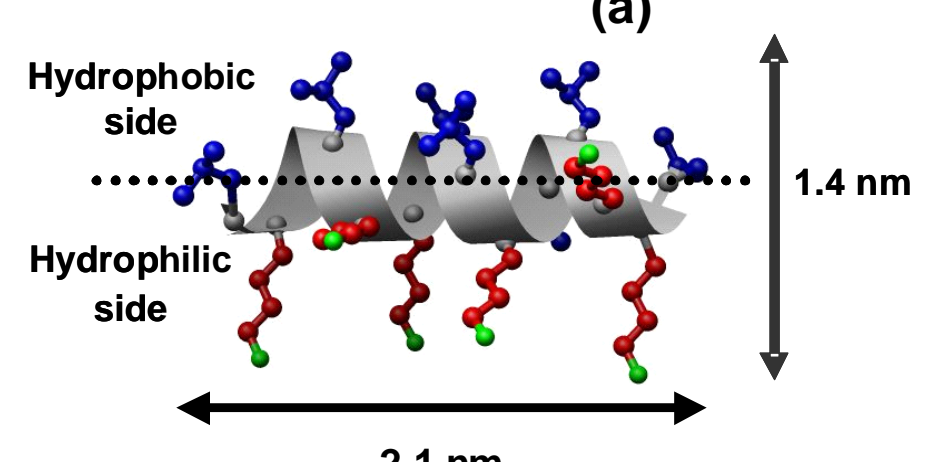<smiles>CC(C)CC(N)C=O</smiles>

N L = Leucine

$2.1 \mathrm{~nm}$

(b)

$$
\mathrm{K}=\text { Lysine }
$$

Ac(LKKLLKLLLKKLLKL) $\mathrm{NH}_{2}$
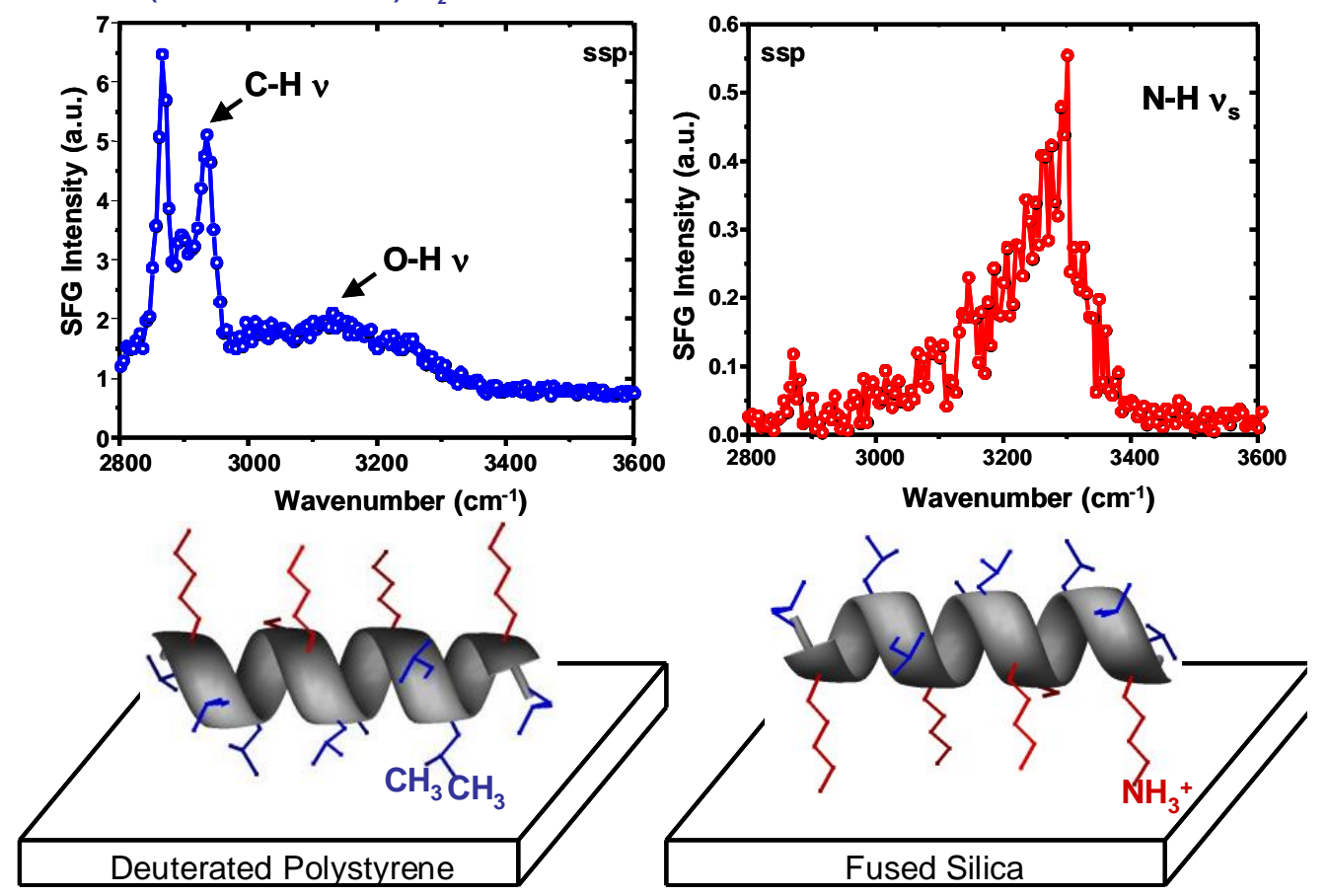

Figure 19. 


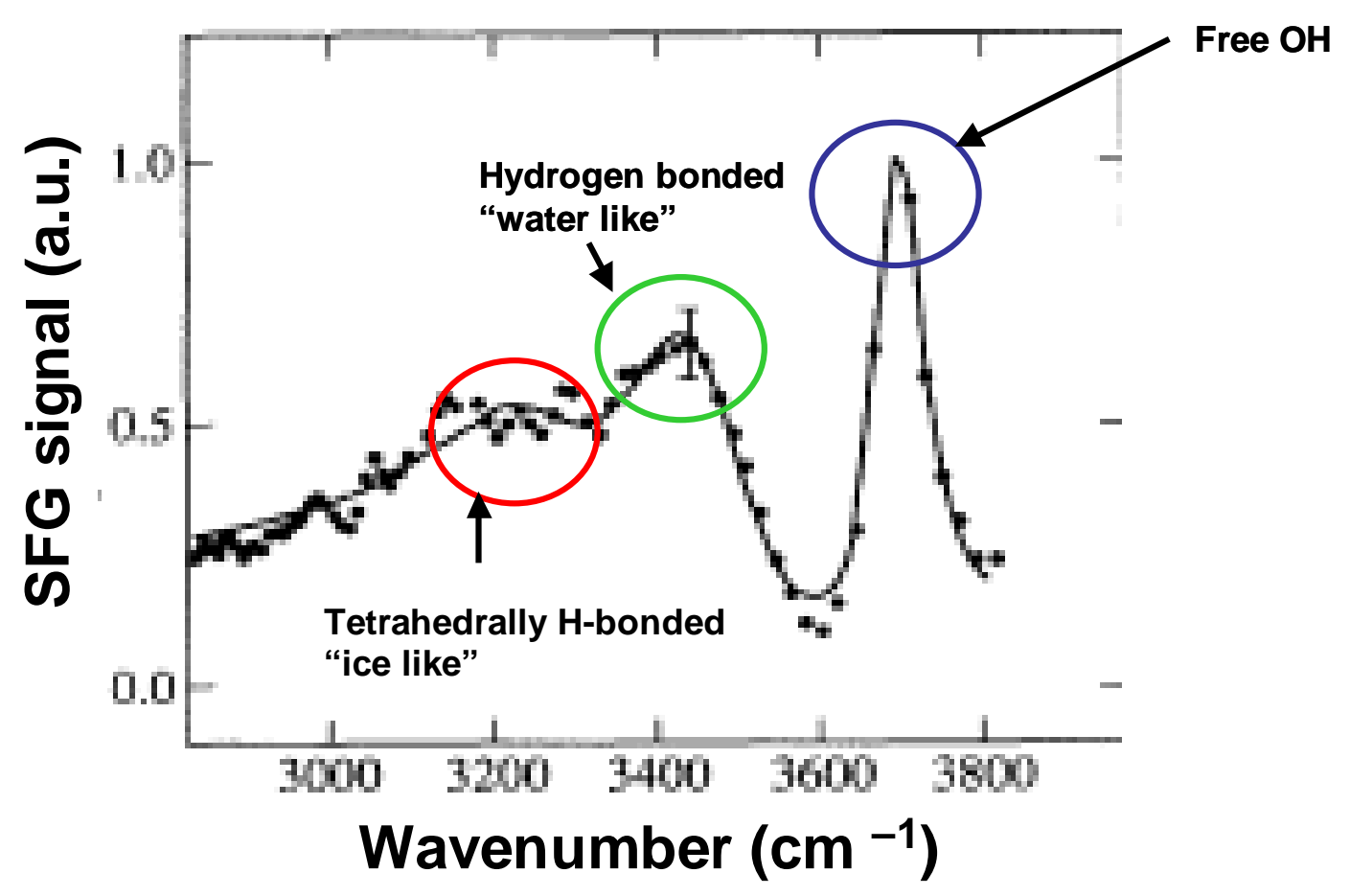

Figure 20. 
(a)

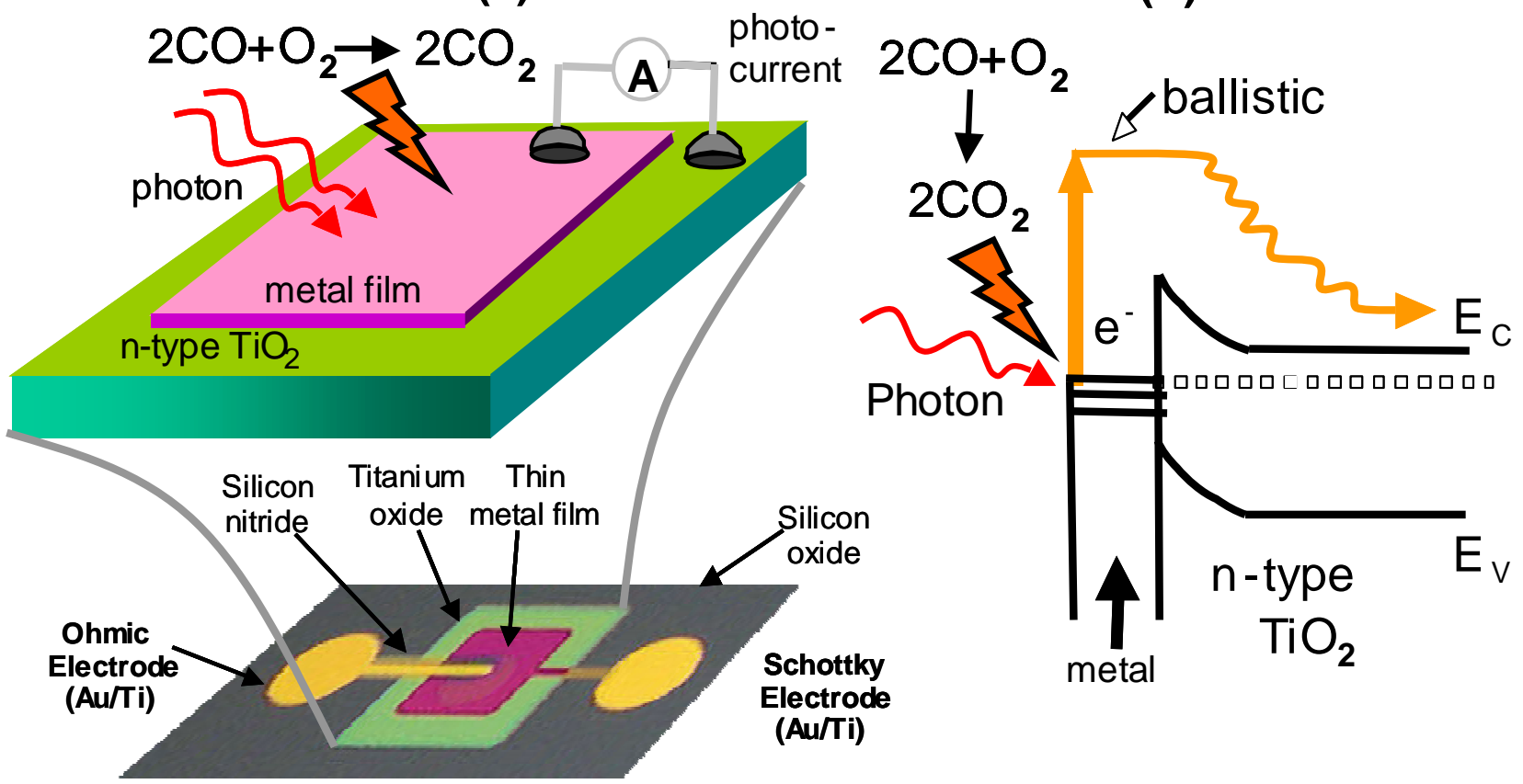

Figure 21. 


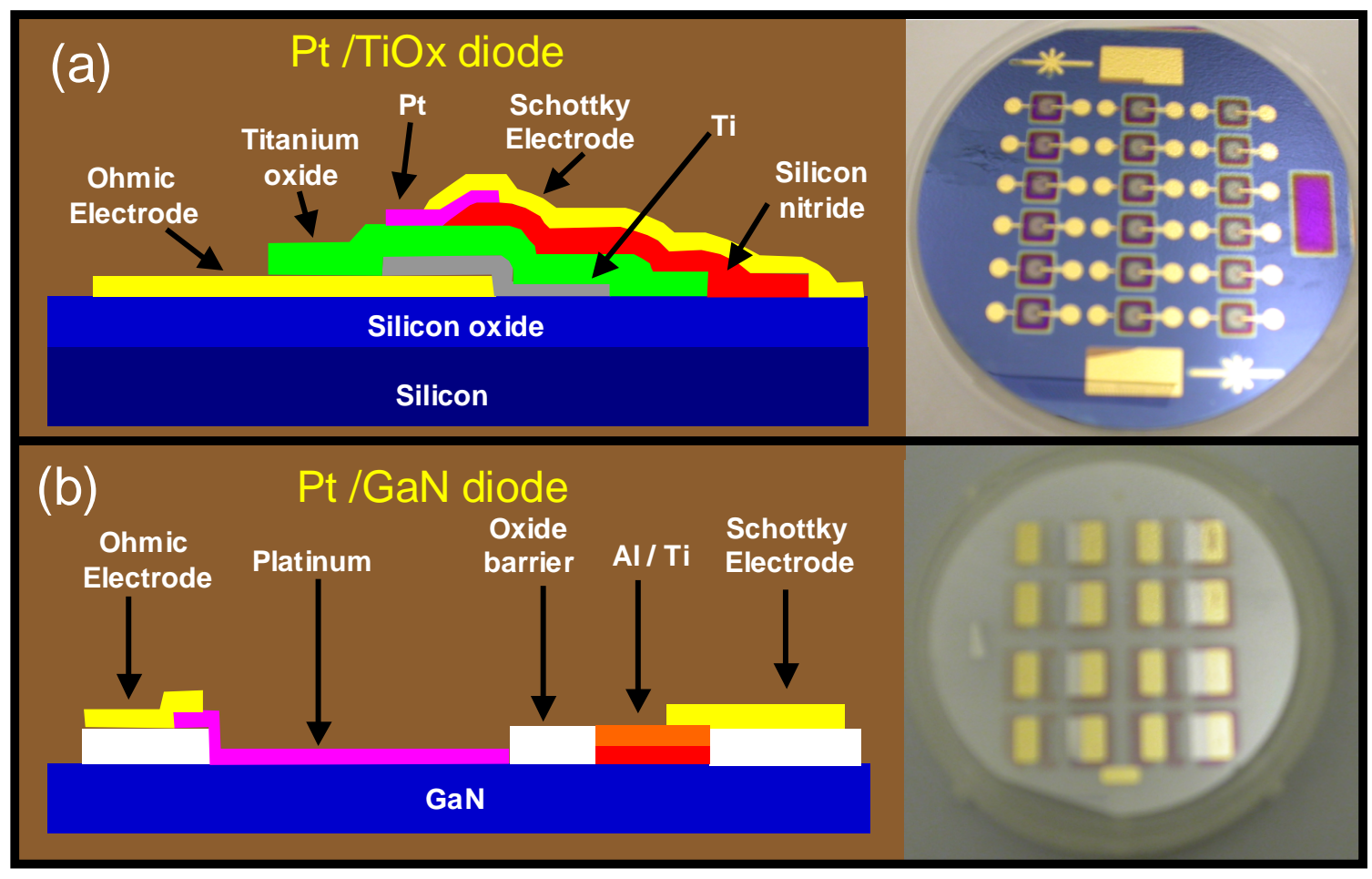

Figure 22. 


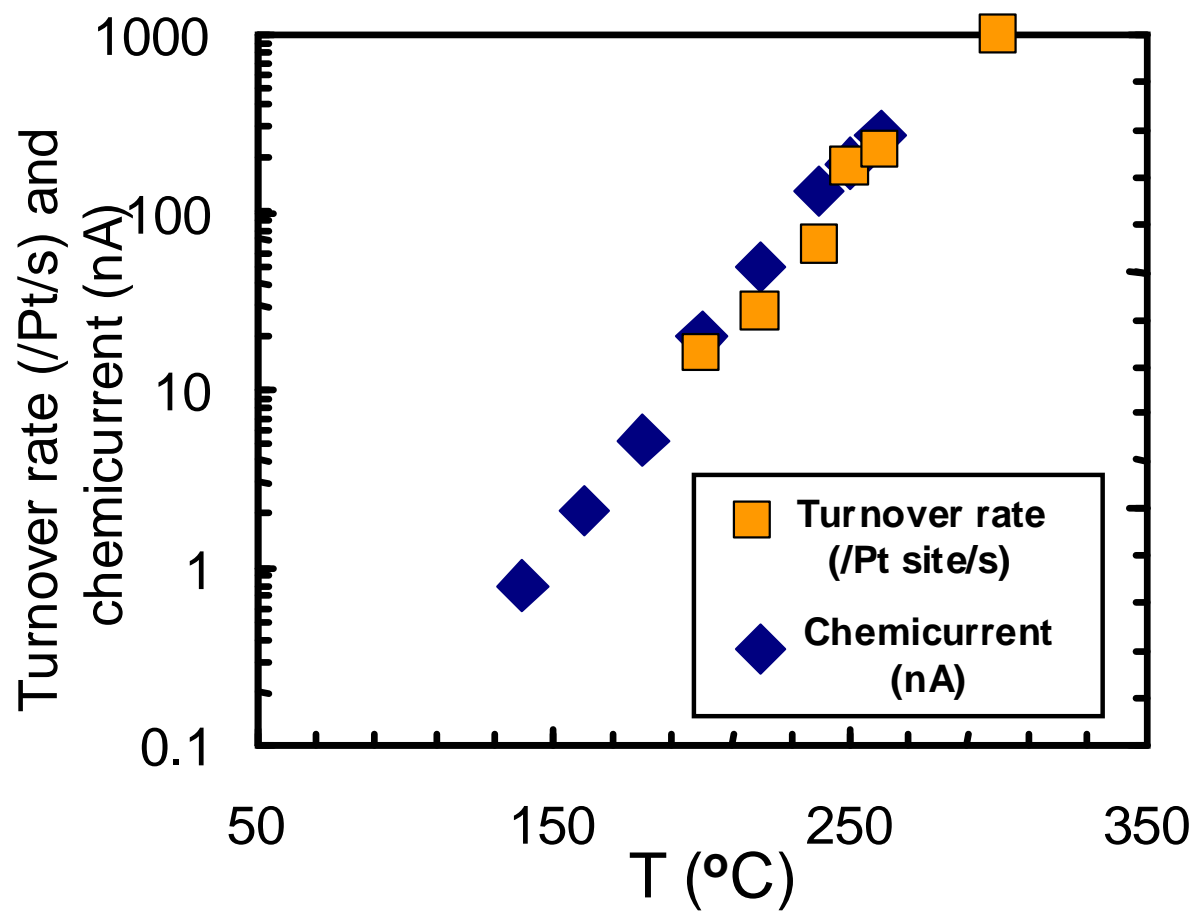

Figure 23. 


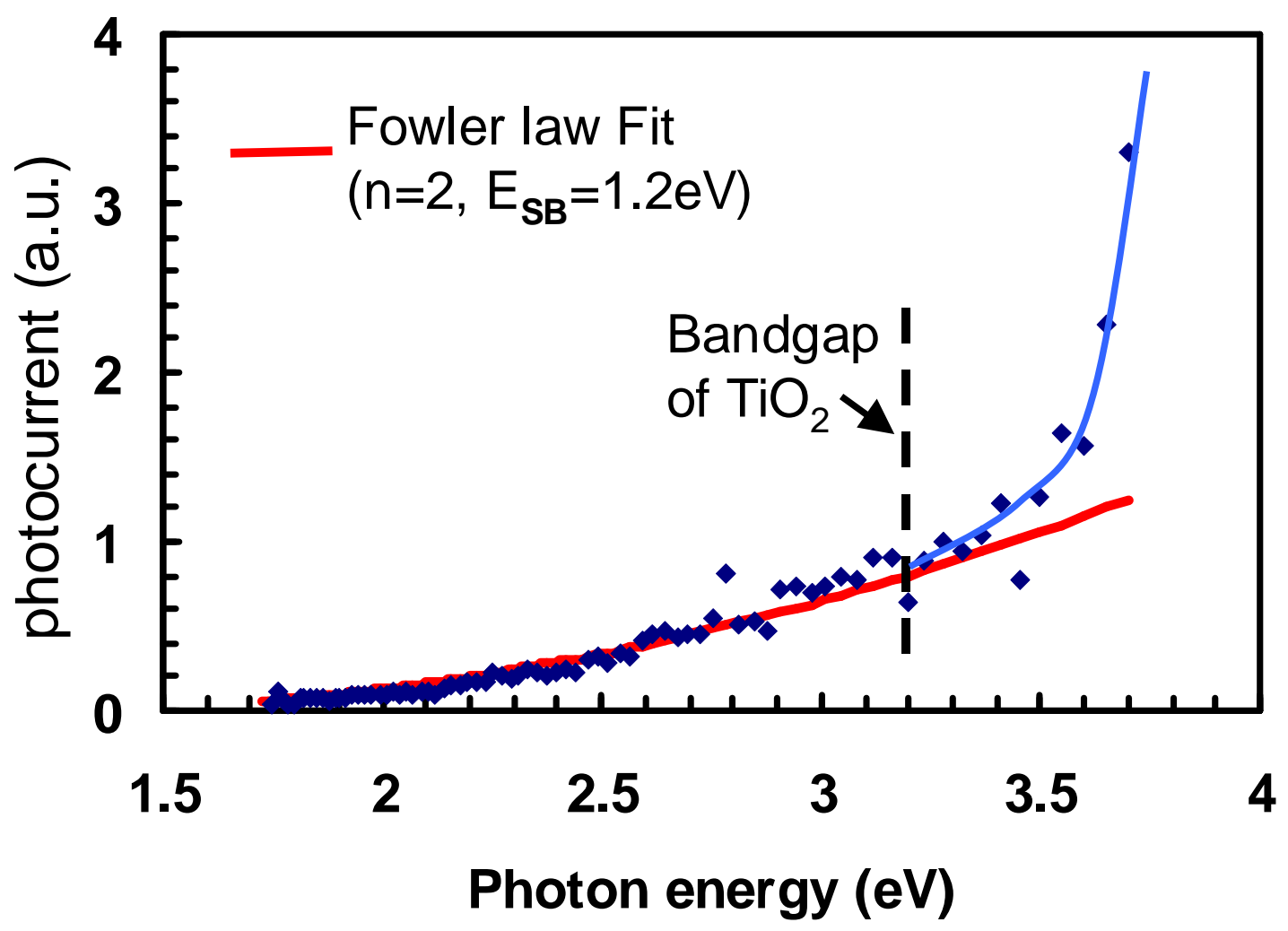

Figure 24. 

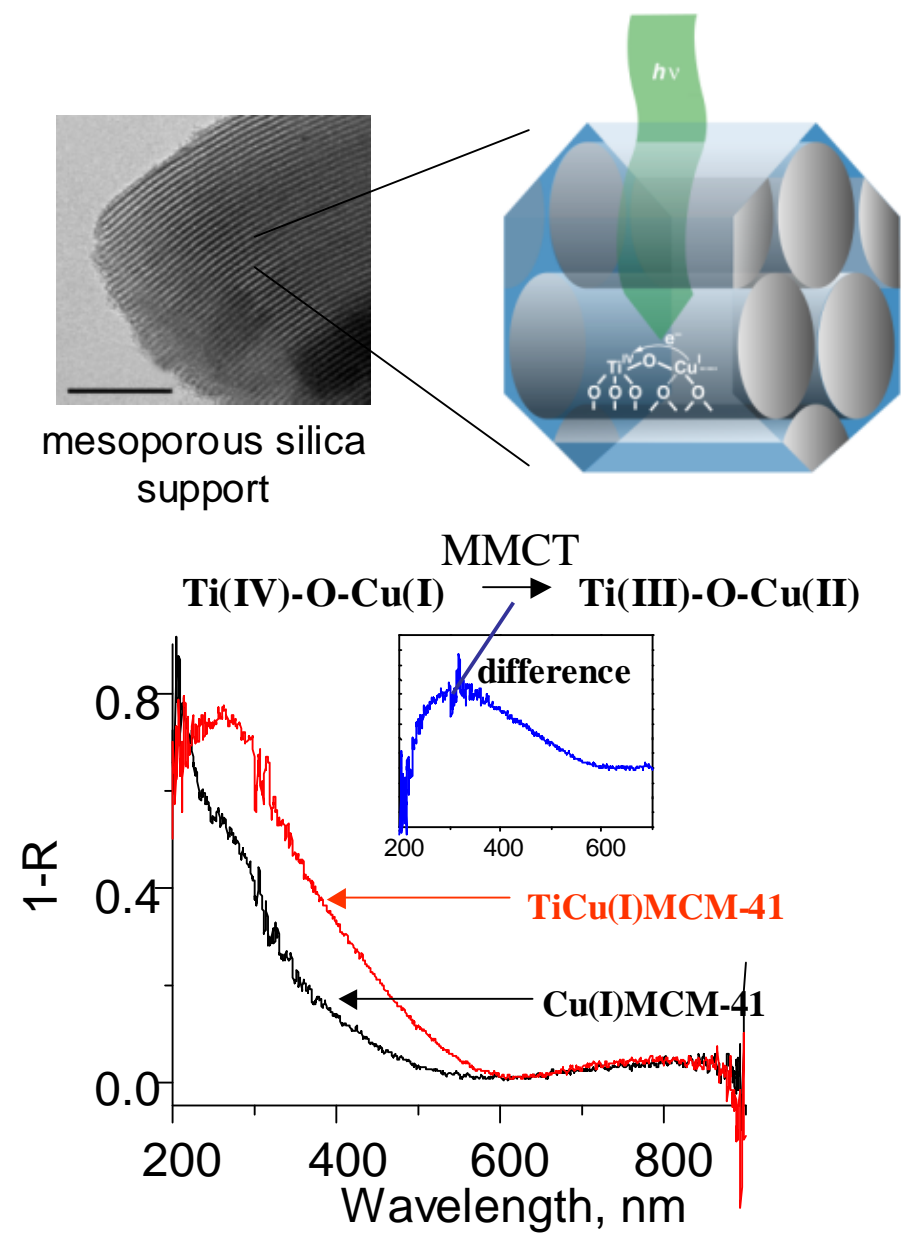

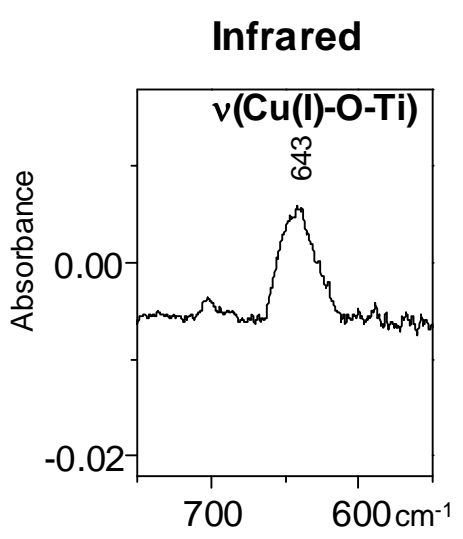

XANES of Ti K-edge

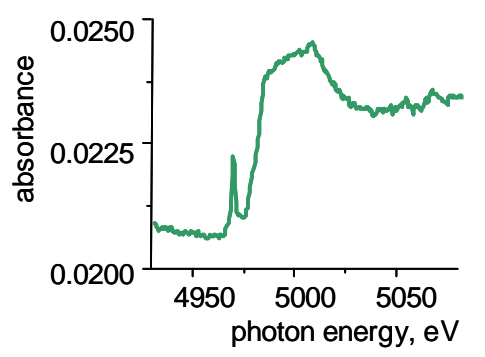

Figure 25. 


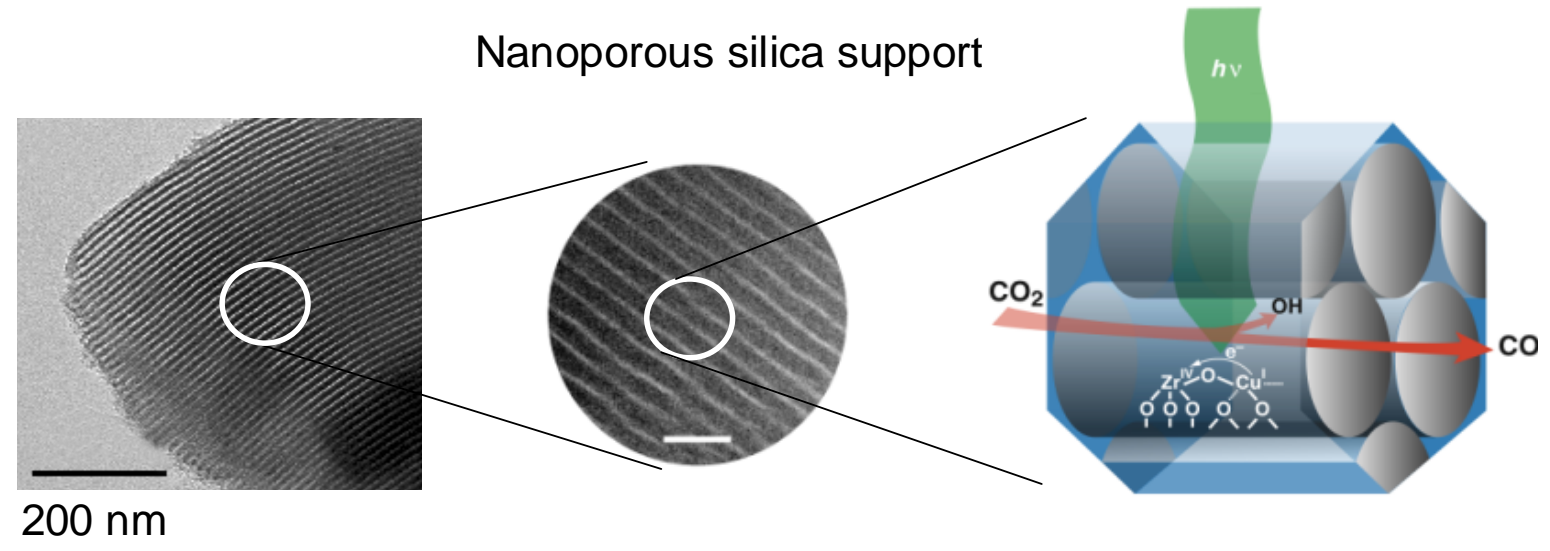

FT-infrared

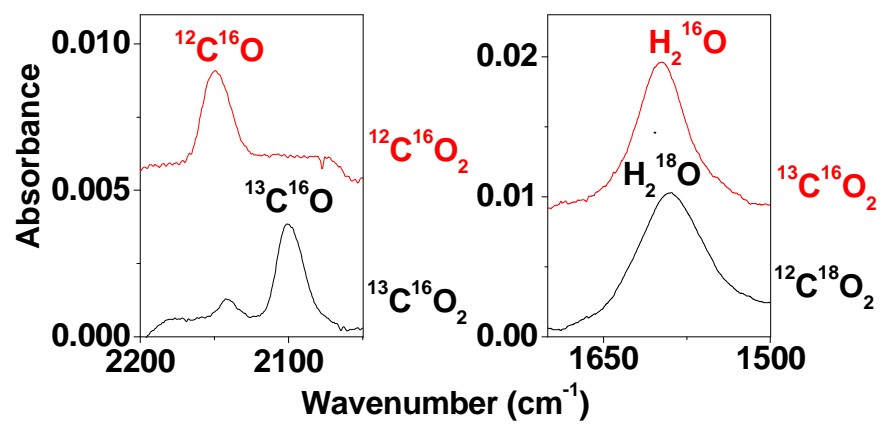

$\mathrm{CO}_{2}+2 \mathrm{Cu}^{\prime}+2 \mathrm{H}^{+} \longrightarrow \mathrm{CO}+\mathrm{H}_{2} \mathrm{O}+2 \mathrm{Cu}^{\prime \prime}$

Figure 26. 
Structure of Water Oxidation Photocatalyst

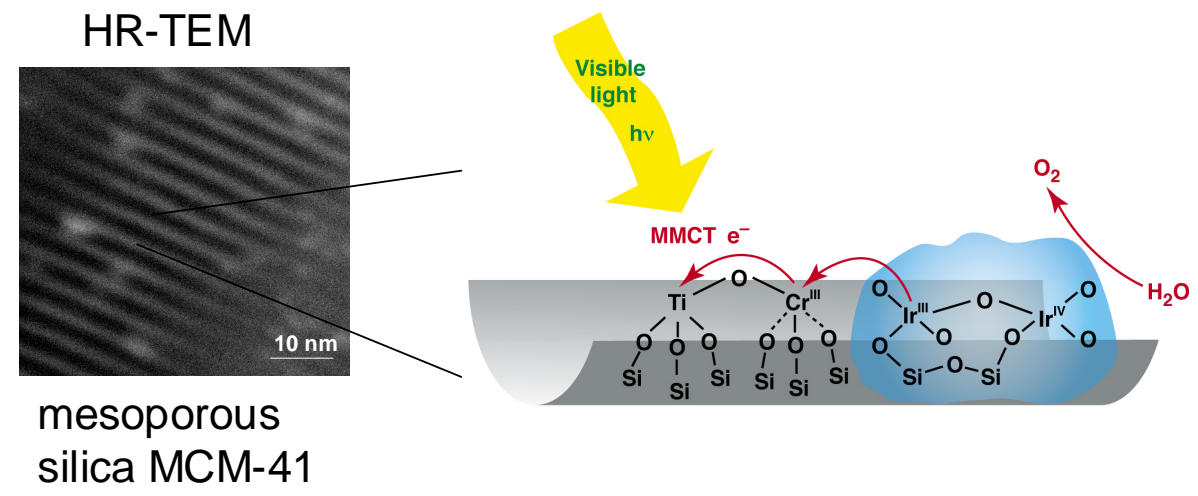

UV-Vis spectrum: MMCT absorption

FT-EXAFS: structure of TiOCr unit
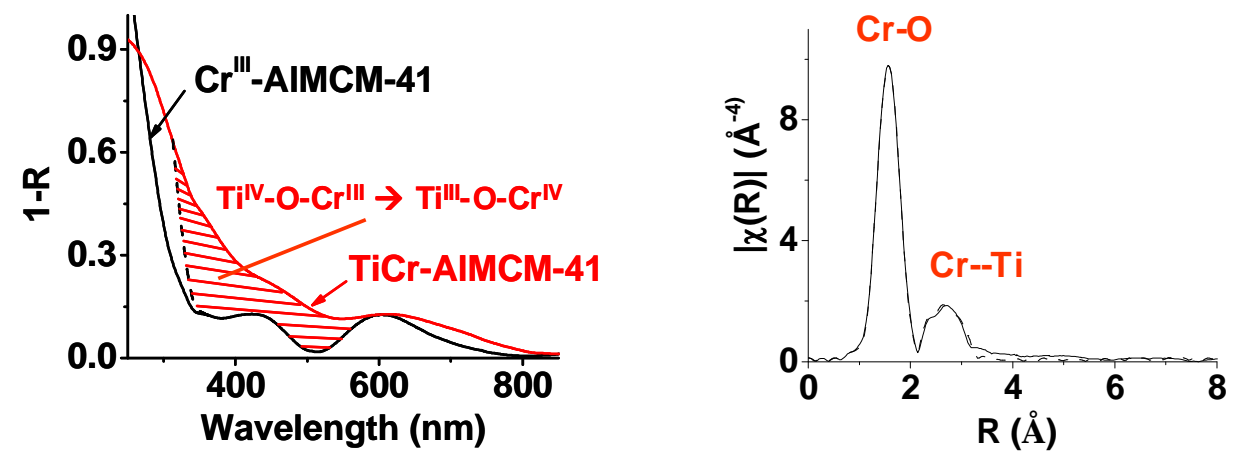

Figure 27. 
Catalytic Water Oxidation with Visible Light

(a) Electrochemical $\mathrm{O}_{2}$ detection

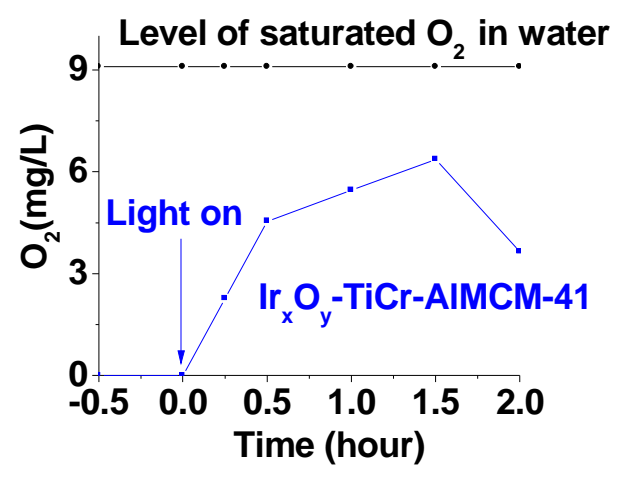

(c)

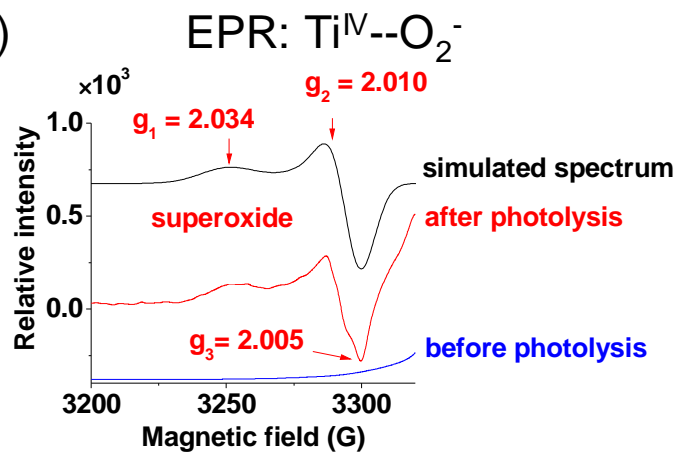

(b) FT-Raman: $\mathrm{O}_{2}^{-}$

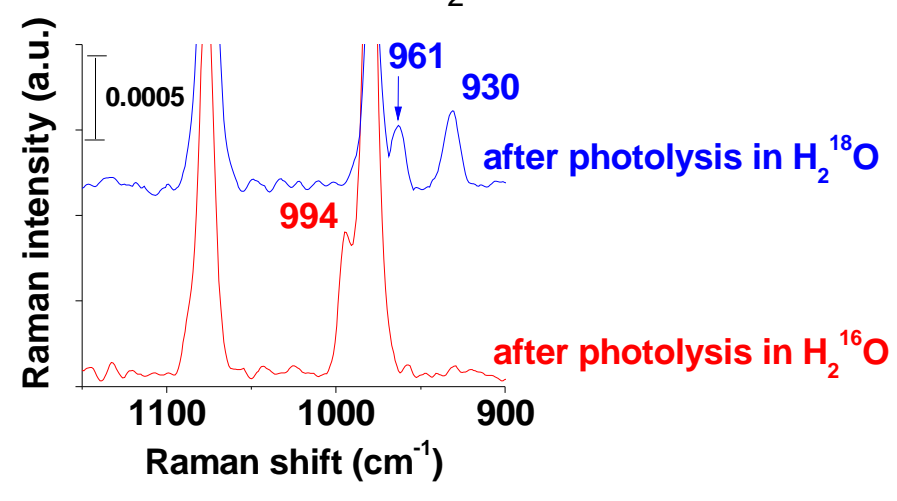

(d) EPR: Till

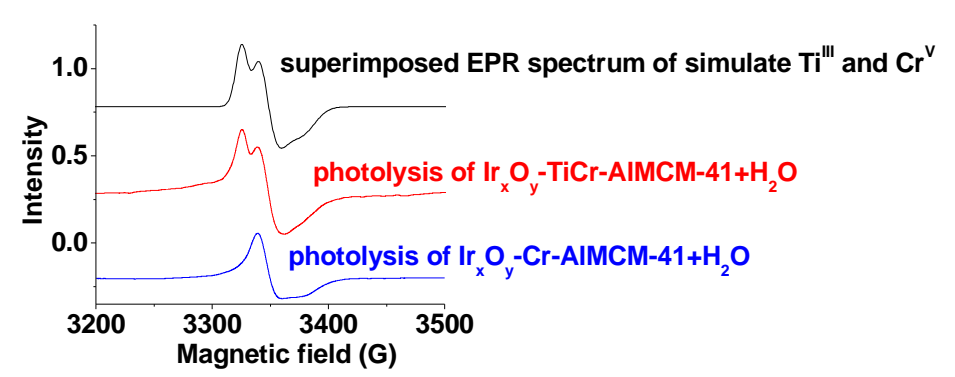

Figure 28. 


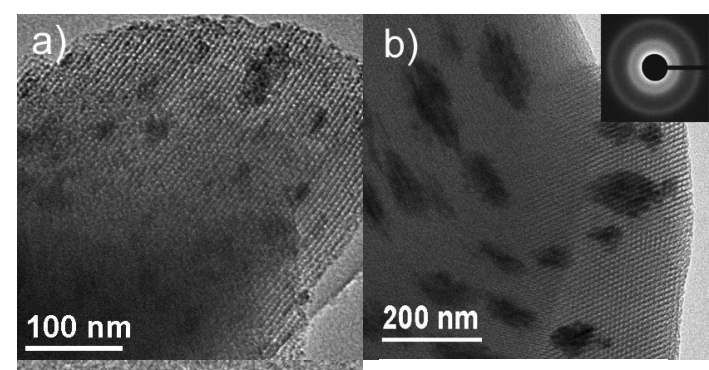

(d)
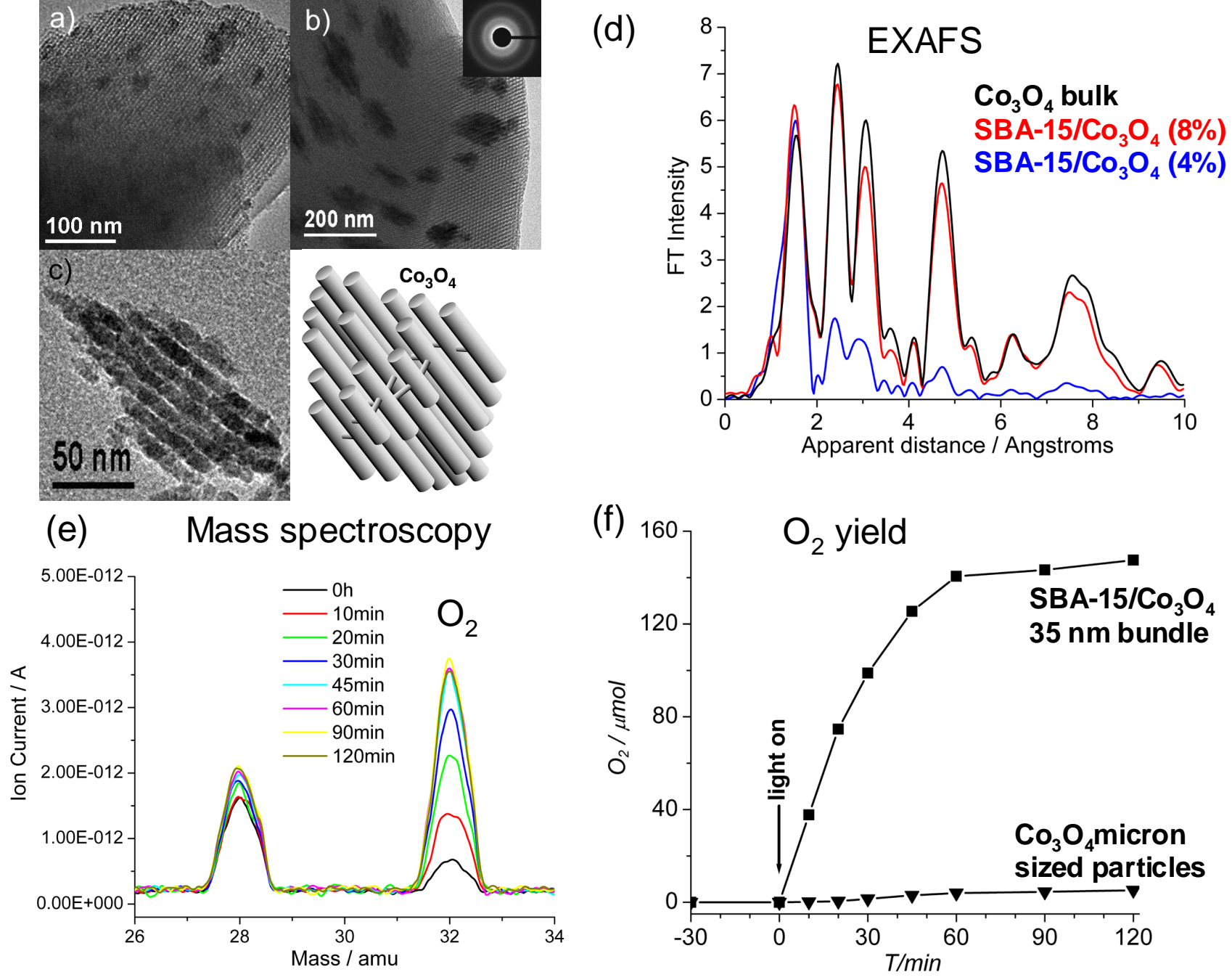

Figure 29. 